NBER WORKING PAPER SERIES

\title{
SCHOOL FINANCE EQUALIZATION INCREASES INTERGENERATIONAL MOBILITY: EVIDENCE FROM A SIMULATED-INSTRUMENTS APPROACH
}

\author{
Barbara Biasi \\ Working Paper 25600 \\ http://www.nber.org/papers/w25600 \\ NATIONAL BUREAU OF ECONOMIC RESEARCH \\ 1050 Massachusetts Avenue \\ Cambridge, MA 02138 \\ February 2019
}

I wish to thank Caroline Hoxby for the valuable advice she has provided me while working on this project. I also thank Jason Abaluck, Joe Altonji, Jaime Arellano-Bover, Leah Boustan, Raj Chetty,Will Dobbie, Florian Ederer, Paul Goldsmith-Pinkam, Robert Jensen, Alan Krueger, Julien Lafortune, Costas Meghir, Petra Moser, Petra Persson, Luigi Pistaferri, David Sch"onholzer, Edoardo Teso, EbonyaWashington, as well as seminar participants at Stanford, Princeton, Yale, EIEF Rome, the Russell Sage Foundation, Barcelona GSE Summer Forum 2018, and the NBER Summer Institute 2018 for helpful comments. The Departments of Education of the states of California, Colorado, Florida, Georgia, Kentucky, Illinois, Louisiana, Massachusetts, Michigan, Minnesota, Nebraska, New Jersey, New York, North Dakota, Ohio, Pennsylvania, Utah, Texas, and Wisconsin provided invaluable help in the retrieval of historical district-level components of school finance formulas. Financial support from the Russell Sage Foundation Award 83-14-06 and from the Gregory Terrill Cox Fellowship and the John M. Olin Program in Law and Economics at Stanford Law is gratefully acknowledged. All mistakes are mine. The views expressed herein are those of the author and do not necessarily reflect the views of the National Bureau of Economic Research.

NBER working papers are circulated for discussion and comment purposes. They have not been peerreviewed or been subject to the review by the NBER Board of Directors that accompanies official NBER publications.

(C) 2019 by Barbara Biasi. All rights reserved. Short sections of text, not to exceed two paragraphs, may be quoted without explicit permission provided that full credit, including $\odot$ notice, is given to the source. 
School Finance Equalization Increases Intergenerational Mobility: Evidence from a Simulated-Instruments Approach

Barbara Biasi

NBER Working Paper No. 25600

February 2019, Revised October 2019

JEL No. I22,I24,J62

\begin{abstract}
This paper estimates the causal effect of equalizing revenues across public school districts on students' intergenerational mobility. I exploit differences in exposure to equalization across seven cohorts of students in 20 US states, generated by 13 state-level school finance reforms passed between 1980 and 2004. Since these reforms create incentives for households to sort across districts and this sorting affects property values, post-reform revenues are endogenous to an extent that varies across states. I address this issue with a simulated instruments approach, which uses newly collected data on states' funding formulas to simulate revenues in the absence of sorting. I find that equalization has a large effect on mobility of low-income students, with no significant changes for high-income students. Reductions in the gaps in inputs (such as the number of teachers) and in college attendance between low-income and high-income districts are likely channels behind this effect.
\end{abstract}

\title{
Barbara Biasi
}

Yale School of Management

165 Whitney Avenue

New Haven, CT 06520

and NBER

barbara.biasi@yale.edu

A data appendix is available at http://www.nber.org/data-appendix/w25600 


\section{Introduction}

Large differences in intergenerational income mobility exist across states and local labor markets in the United States. The probability that a child born in a family in the bottom quintile of the national income distribution will reach the top quintile during adulthood is 14.3 percent on average in Utah, but only 7.3 percent in Tennessee (Chetty et al., 2014). While part of these differences might be due to different types of people self-selecting into specific places, studies of movers across counties have highlighted a causal relationship between growing up in certain areas and long-run outcomes (Ludwig et al., 2013; Chetty et al., 2016; Chetty and Hendren, 2018a).

Less is known, however, about what factors make a place particularly successful at guaranteeing equal opportunities to children regardless of their family background. Places with high intergenerational mobility tend to have lower income and racial segregation, lower inequality, higher social capital, and better schools (as proxied by test scores, Chetty and Hendren, 2018b). While these patterns are suggestive of a role for institutions and public policies in promoting mobility, they cannot be interpreted as causal. Yet, understanding the role of public policies is the first step towards improving intergenerational mobility and guaranteeing equal opportunities to all children regardless of their family background.

This paper moves beyond these simple correlations and examines the causal role of school finance equalization, i.e., a reduction in the differences in public school revenues and expenditures across school districts within a state. Historically, US schools have been primarily funded with revenues from local levies (such as property taxes). As a consequence, wealthier districts (with a larger tax base) have been able to spend more per pupil than poorer districts. These between-district disparities vary across states: In 1980, the gap in expenditure between the lowest-spending and the highest-spending district was 70 percent in California, but only 40 percent in Maryland. This variation is driven by cross-state differences in funding formulas, used to define each district's revenues as a combination of state funds and local levies. In an attempt to equalize expenditures, over the past four decades states have reformed their school finance schemes through changes in these formulas. While often sharing a common objective, however, school finance equalization reforms have taken various forms across states and over time, with some being more successful at equalizing revenues than others (Hoxby, 2001).

To study the causal effects of equalization on children's intergenerational mobility, I exploit 
changes in the distribution of per pupil revenues generated by 13 state-level school finance reforms passed in a sample of 20 states between 1980 and 2004. I use the measure of intergenerational mobility of Chetty et al. (2014) (also used by Acciari et al., 2019), defined as a child's percentile in the national income distribution given the income percentile of their parents, and calculated separately for each commuting zone (CZ hereafter), cohort (1980-1986), and income percentile of the parents. I measure equalization in school revenues as the slope of the relationship between per capita income and per pupil revenues across districts in each state, denoted by $\beta$ (as in Hoxby, 1998; Card and Payne, 2002; Lafortune et al., 2018). When revenues are perfectly equalized, $\beta$ equals zero; when wealthier districts receive and spend more, $\beta$ is positive.

I show that school finance reforms led to a sharp decline in $\beta$, i.e., to a reduction in the difference in school revenues between districts serving children from poorer and wealthier families. A simple theoretical framework predicts that this decline, which breaks the link between parents' economic conditions and school spending on their children, should improve the economic opportunities of lower-income children relative to those of their parents, "leveling the playing field" (Becker and Tomes, 1994). ${ }^{1}$

To empirically investigate the effects of equalization on intergenerational mobility, I exploit the fact that different cohorts were in school during different years and therefore experienced different degrees of equalization (different $\beta$ ) across states. For example in Wisconsin, which had a reform in 1996, the 1980 cohort (in school between 1986 and 1998) had a $\beta$ equal to 0.016 (with the richest district spending $\$ 15,000$ and the poorer district spending $\$ 10,000$ in 1990), while the 1990 cohort (in school between 1996 and 2008) had a $\beta$ equal to 0.008 (with the richest district spending $\$ 13,000$ and the poorer district spending $\$ 14,000$ in 2000). In Ohio, which had no reform between 1986 and 2004, these two cohorts had a $\beta$ equal to 0.044 and 0.047 , respectively. Assuming that the timing of each reform is exogenous, comparing intergenerational mobility across cohorts within each state allows me to estimate the effects of equalization. In support of this assumption, I show that mobility was on a flat trend in the years leading to a reform in each state. ${ }^{2}$

To causally estimate the effects of a decline in $\beta$ on mobility, however, one must deal with

\footnotetext{
${ }^{1}$ Existing research has shown that early investments in human capital are among the major determinants of future income (Becker and Tomes, 1979), especially for disadvantaged children (Cunha et al., 2010).

${ }^{2}$ This assumption has also been extensively discussed and argued for by Hoxby (2001); Lafortune et al. (2018); Jackson et al. (2015).
} 
an endogeneity problem. The changes in the funding formula that lead to changes in $\beta$ alter the relationship between the "price" of school spending to taxpayers and the amount of public good they receive in return. This might induce households to "vote with their feet" (Tiebout, 1956), i.e., to move across districts based on their preferences for this public good and their income. ${ }^{3}$ On one side, household sorting affects house prices and districts' revenues (via the funding formula) and the degree of equalization in school funding. On the other side, this sorting changes the composition of each school district and CZ, which could have a direct effect on mobility (for example through peer effects). Post-reform revenues - and the resulting $\beta$ - are therefore endogenous; ignoring this endogeneity would confound the effects of equalization with the effects of sorting.

I address this endogeneity issue with a simulated-instruments approach (similar to Gruber and Saez, 2002), which exploits plausibly random, state-specific changes in the funding formulas. To do this, I combine a variety of administrative and legislative sources to construct an original data set containing information on the formulas in place in each state and year and on all the district-level variables entering each formula. This information is available for a sample of 20 states, enrolling 62 percent of all US students. These data allow me to simulate district revenues in the absence of sorting, using the post-reform formula but keeping districts' characteristics (e.g. property values, enrollment, and income) fixed at their pre-reform values. I then use these simulated revenues to estimate a simulated version of $\beta$, which I use as an instrument for $\beta$.

This approach is useful for two reasons. First, it allows me to separate the variation in the distribution of school revenues driven by exogenous changes in the funding formula from the variation driven by endogenous household sorting, which is necessary to estimate causal effects. Second, it explicitly takes into account the fact that different reforms had very different effects on the level and distribution of school revenues across districts, because they changed the funding formulas in very different ways (as shown by Hoxby, 2001; Jackson et al., 2015; Hyman, 2017, and also evident in my data). Ignoring this heterogeneity could impact both the precision and the consistency of the estimates. ${ }^{4}$

\footnotetext{
${ }^{3}$ Aaronson (1999); Dee (2000); Figlio and Lucas (2004); Epple and Ferreyra (2008); Chakrabarti and Roy (2015) provide evidence of this type of sorting in various contexts.

${ }^{4}$ Importantly, both the changes in spending inequality and the patterns of household sorting triggered by each reform depend on the pre-reform and post-reform funding formula (Hoxby, 2001). For example, Jackson et al. (2015) find that school finance reforms increase expenditure more in ex ante lower-spending districts, whereas Hyman (2017) finds that a reform passed in Michigan in 1993 increased expenditure more in low-poverty districts. In line with these results, I find that some reforms (such as Massachusetts, 1994 and Wisconsin, 1996) led to larger
} 
Two-stages least squares (2SLS) estimates of the effects of changes in $\beta$ indicate that school finance equalization has a sizable positive effect on intergenerational mobility. A one-standard deviation reduction in $\beta$ (equivalent to a $\$ 4,500$ reduction in the difference in per pupil revenues between the richest and the poorest districts in a state) leads to a significant 5.6 percentile increase in the income rank of children with parental income in the 10th percentile; this estimate correspond to a 16.2 percent increase in income. By comparison, the same reduction in $\beta$ has a smaller and insignificant effect on children with parents in the 90th income percentile. These results are robust to controlling for total school spending in each state. My results also indicate that the average reform would increase mobility of children from families in the 10th percentile by 3.6 percentiles (or 8.6 percent), and close approximately 13 percent of the gap between the lowest-mobility and the highest-mobility CZ. ${ }^{5}$ Importantly, 2SLS estimates are approximately 50 percent larger than both a) OLS estimates and b) estimates obtained ignoring the differences in the funding formulas across states.

My estimates also show that equalization is most effective when experienced earlier in a child's education career. A one-standard deviation reduction in $\beta$ increases the income rank of children with parents in the 10th percentile by 7.6 percentiles if the reform that generated this decline was experienced during elementary school, but only 4.1 percentiles if it was experienced during high school. This finding is in line with a large literature highlighting the importance of early childhood investments for long-run outcomes (see Cunha and Heckman, 2010, for a review).

The effects of equalization in school revenues might vary depending on the degree of income inequality and segregation within each CZ. When cross-district income inequality is high, the same reduction in $\beta$ might translate into a much larger increase in revenues in lowerincome districts relative to higher-income ones. Similarly, when segregation is high, a reduction in $\beta$ is more likely to increase revenues for lower-income children. 2SLS estimates confirm that a decline in $\beta$ has the largest effects on CZs with higher income inequality and higher levels of segregation.

In the last part of the paper I explore the channels behind the main estimates. I provide sug-

declines in $\beta$ compared with others (such as Michigan, 1993). Furthermore, different reforms triggered different changes in house prices: A reform in New Jersey in 1990 led to a decline in overall prices, the one in Massachusetts lead to an increase, and the one in Michigan left prices unchanged.

${ }^{5}$ The average reform reduces $\beta$ by approximately 0.045 (Figure I), or 0.64 of a standard deviation. The effect of this decline on the mobility of children with parents in the 10th percentile is an increase of approximately 3.6 percentiles, which corresponds to 13 percent of the 27.6 percentile gap in mobility between the highest-mobility $\mathrm{CZ}$ (Sioux Center, IA) and the lowest-mobility one (Clarksdale, MS). 
gestive evidence that school finance equalization increases intergenerational mobility through a reduction in the gaps in basic school inputs (such as the number of teachers) and in intermediate educational outcomes (such as college enrollment) between richer and poorer districts.

This paper makes three main contributions. First, it provides a causal explanation for the differences in intergenerational mobility across US areas illustrated by Chetty et al. (2014). ${ }^{6}$ Existing empirical evidence on the effectiveness of increased education expenditure (see, for example, Cascio et al., 2013; Cascio and Reber, 2013) or on expansion in access to high-quality education (Meghir and Palme, 2005; Pekkarinen et al., 2009; Havnes and Mogstad, 2015) in closing gaps in outcomes among more and less advantaged students suggests a positive role for school finance equalization in improving intergenerational mobility. At the same time, Rothstein (2019) argues that differences in school quality do not seem to explain much of the observed differences in mobility and suggests that attention should be placed on other types of policies. While Rothstein's findings are based on correlations, this paper shows that a schoolrelated policy such as school finance equalization causes a sizable improvement in long-term outcomes of economically disadvantaged children, in line with Card et al. (2018). This implies that equalization can be an engine for mobility, even if it explains a relatively small share of the cross-sectional variation. My results also shed some light on the mechanisms through which equalization in school resources affect children's long-run outcomes, such as equalization in school inputs and in college attendance.

Second, this paper contributes to a large literature on the effects of school spending on students' outcomes, initiated decades ago by the Coleman report (Coleman et al., 1966) and encompassing observational (Hanushek, 1986, 1997, 2003), quasi-experimental (Card and Krueger, 1992; Hyman, 2017), and experimental studies (Krueger, 1999; Dynarski et al., 2013). A few studies in this literature have used school finance reforms as a source of variation in the levels of school expenditures to study the effects on short-term absolute outcomes, such as student achievement and educational attainment (Hoxby, 2001; Card and Payne, 2002; Hyman, 2017; Lafortune et al., 2018), and long-term outcomes, such as earnings (Jackson et al., 2015). This paper extends this literature by focusing on intergenerational mobility, a measure of economic

\footnotetext{
${ }^{6}$ Most of the earlier literature on intergenerational mobility is descriptive and has focused on comparing various measures across countries and using different samples within each country. Early studies have looked at the correlation in earnings of parents and children at a single point in time (Becker and Tomes, 1994). Subsequent works (surveyed in Solon, 1999) have tried to obtain more precise estimates using panel data and isolating the permanent component of lifetime income. Another related strand of research has attempted to perform international comparisons of intergenerational income elasticities (Solon, 2002).
} 
opportunity which has received increasing attention in recent years thanks to the availability of administrative tax data (Chetty et al., 2014; Acciari et al., 2019). As mobility is an inherently relative concept, designed to capture the relationship between children's and parents' outcomes, the focus of my analysis is on the effects of revenue equalization (rather than revenue levels), the key parameter that governs the extent to which investments in public education depend on parents' economic status.

Lastly, and perhaps most importantly, this paper highlights the importance of accounting for the endogeneity in post-reform expenditure and for the differences in funding schemes across states when studying the effects of changes in spending driven by school finance reforms. To capture these differences, Jackson et al. (2015) instrument expenditure with the timing and "type" (e.g. foundation plan, or equalized effort) of each reform. Even this approach, however, is unable to fully account for the fact that even reforms of the same type could have affected the distribution of revenues and expenditures in different ways and triggered different household responses. My estimates demonstrate that ignoring these differences can lead to the inconsistent estimation of the effects of equalization. My approach, and the accompanying dataset, can be used in other settings as well.

The rest of the paper proceeds as follows. Section 2 describes the school finance equalization reforms. Section 3 uses a simple theoretical framework to illustrate the relationship between school finance equalization and intergenerational mobility. Section 4 describes the data. Section 5 introduces the measure of inequality in school revenues. Section 6 outlines the simulated instruments approach. Section 7 presents and discusses the main estimates of the effects of equalization on intergenerational mobility. Section 8 investigates the mechanisms behind these effects, and Section 9 concludes.

\section{School Finance Equalization Reforms}

US school districts have historically drawn a large portion of their revenues from local property taxes (Howell and Miller, 1997; Hoxby, 2001). As a result, wealthier districts - with a larger tax base - have been able to spend considerably more compared to low-income districts. Over time, this has created large disparities in per pupil revenues and expenditures across districts within each state. Capitalization of the quality of public schools into house prices has exacerbated these differences. 
To reduce these disparities, states have passed school finance equalization reforms. Some of these reforms followed rulings of unconstitutionality of funding schemes by states' Supreme Courts. Others were instead the outcomes of legislative processes. Earlier reforms, passed in the 1970s and 1980s, had a predominant equity motive and were designed to weaken the relationship between each district's fiscal capacity and the amount of resources spent on public schools (Card and Payne, 2002; Murray et al., 1998; Jackson et al., 2015). Later reforms have focused more on adequacy, i.e., have sought to guarantee a minimum level of expenditure to children in all districts (Lindseth, 2004; Lafortune et al., 2018).

Regardless of their specific motives, school finance equalization reforms have changed states' funding schemes, typically summarized by a formula. This formula expresses a district's total revenue as a function of a number of variables, including (but not limited to) enrollment, fiscal capacity, and fiscal effort (i.e., local tax rates). The formulas also define the size of state transfers to each school district, and some include limits on total spending or local tax rates. Hoxby (2001) and Jackson et al. (2014) provide a categorization of school finance plans into a number of "types," depending on whether they focus on ensuring a minimum level of expenditure ("foundation" or "equalization" plans), guaranteeing a certain tax base ("guaranteed tax base"), or providing incentives toward fiscal effort ("rewards for effort"). Nearly all funding formulas are, however, the combination of two or more of these types. In addition, the parameters of each formula vary considerably across states and over time even within types. As a result, plans passed under the same name have had very different effects on districts' revenues and expenditures.

One common aspect of different school finance schemes is that the basis for equalization, i.e., the tax base, is endogenous. A change in the funding formula provides households with incentives to sort across school districts depending on their preference for public schools and their income; these movements affect house prices and district revenues. The failure of policymakers to fully understand and anticipate these responses when designing school finance plans has caused some reforms to reduce overall expenditure on public schools (or "level down"; Hoxby, 2001). ${ }^{7}$

Empirical evidence on the effects of school finance equalization reforms on student achievement is mixed. Card and Payne (2002) find that court-mandated reforms reduced gaps in SAT

\footnotetext{
${ }^{7}$ For example, California's 1978 Serrano reform was followed by an unprecedented decline in expenditure (Silva and Sonstelie, 1995). Similarly, Texas's 1993 “Robin Hood" plan is estimated to have destroyed $\$ 27,000$ per pupil in property values (Hoxby and Kuziemko, 2004).
} 
scores between low-income and high-income students. More recently, Lafortune et al. (2018) estimate a positive and large effect of adequacy reforms on test scores. ${ }^{8}$ In one of the few studies of the long-run effects of school finance reforms, Jackson et al. (2015) find large effects of increased expenditure on future educational achievement, wages, and poverty incidence among low-income students. This paper focuses on the effects of equalization in school revenues (as opposed to changes in revenue levels) on students' intergenerational income mobility. The goal is to quantify the extent to which breaking the link between parental resources and public school spending breaks the link between parents' and children's economic outcomes.

\section{A Simple Model of School Finance and Intergenerational Mobility}

To conceptually illustrate the relationship between school finance equalization and intergenerational mobility, I use a very simple model. This model yields a testable prediction which I bring to the data in the remainder of the paper.

The world is populated by two generations: parents, with income $x$, and children, with income $y$. Parents and children live in school districts and each district belongs to a state. School districts are responsible for the financing of public schools, and each child attends school in the district she lives in. The income of a child in family $i$, living in school district $d$ and state $s$, is determined as follows:

$$
y_{i d}=\theta x_{i d}+\gamma e_{d}
$$

where $x_{i d}$ is parental income and $e_{d}$ is public expenditure on the child's education. The parameter $\theta$ captures all the possible ways in which parental income is related to children's income (e.g. transmission of ability or private investments in education). By expressing the child's income in this way, I implicitly assume that the returns to public education investments are constant across children.

School spending in district $d$, located in state $s$, is defined by the following state-level formula:

$$
e_{d}=\left(1-\beta_{s}\right) K_{s}+\beta_{s} x_{d}
$$

where $K_{s}$ is a state-level constant and $x_{d}$ is average parental income in district $d$. In this ex-

\footnotetext{
${ }^{8}$ Some studies focusing on individual states have also found positive effects of equalization on achievement (Guryan, 2001; Papke, 2005; Roy, 2011) and educational attainment (Hyman, 2017). Downes et al. (1997), on the other hand, find no effects of equalization on the distribution of test scores, and Hoxby (2001) finds mixed evidence on high school dropout.
} 
pression, the parameter $\beta_{s}$ captures the degree of equalization in school expenditure within each state. When $\beta_{s}=0, e_{d}=K_{s}$ : expenditure is fully equalized across all districts in state $s$. When $\beta_{s}>0$, on the other hand, $e_{d}$ depends positively on $x_{d}$, which implies that the richer districts in the state have higher expenditures and vice versa. Lastly, when $\beta_{s}<0$ the system is redistributive and poorer districts receive and spend more.

The income of the child can be rewritten as a function of $K_{s}$ and $\beta_{s}$ as follows:

$$
y_{i d}=\theta x_{i d}+\gamma K_{s}+\gamma \beta_{s}\left(x_{d}-K_{s}\right)
$$

This simple conceptual framework can be used to highlight the relationship between intergenerational income mobility and inequality of school expenditure across districts, captured by the parameter $\beta_{s}$. Following Chetty et al. (2014), I define intergenerational mobility as a child's income rank (in the national distribution) given the income rank $r$ of her parents:

$$
M_{s}^{r}=F_{y}\left(y_{i d} \mid F_{x}\left(x_{i d}\right)=r / 100\right)
$$

where $F_{y}(\cdot)$ represents the national cumulative distribution function (CDF) of children's income and $F_{x}(\cdot)$ denotes the national CDF of parents' income. I make the simplifying assumption that $x_{i d}=x_{d}$ for every individual $i$ living in district $d$. Denoting the quantile function of the random variable $z$ as $Q_{z}(\cdot)^{9}$ and substituting the expression for the child's income from equation (1) allows me to express mobility as a function of the parameter $\beta_{s}$ :

$$
M_{s}^{r}=F_{y}\left(\theta Q_{x}(r)+\gamma K_{s}+\gamma \beta_{s}\left(Q_{x}(r)-K_{s}\right)\right)
$$

Being a CDF, the function $F_{y}(\cdot)$ is non-decreasing. As result, $M_{s}^{r}$ is non-increasing in $\beta_{s}$ when $Q_{x}(r) \leq K_{s}$. Equation (5) implies that a stronger positive correlation between per pupil expenditure and per capita income across districts within a state (i.e., a larger $\beta_{s}$ ) is associated with lower intergenerational mobility for all children with parental income below a state-specific threshold $K_{s}$; furthermore, this association is stronger the lower is parental income. By the same token, a larger $\beta_{s}$ is associated with higher intergenerational mobility for children with parental income greater than $K_{s}$. An important corollary of this result is that, if $K_{s}$ is large enough that all parents in the state have incomes below this threshold, a given decline in $\beta_{s}$

\footnotetext{
${ }^{9}$ Note that $Q_{z}(a)=F_{z}^{-1}(a)$.
} 
would not lead to a decline in mobility (defined relative to the national distribution) even for children of the richest parents in the state. In the remainder of the paper I empirically test these predictions by studying the effects of a decline in $\beta_{s}$, triggered by school finance reforms, on intergenerational mobility of children with low and high parental incomes.

\section{Data}

To conduct the empirical analysis I combine data from multiple sources. In the final data set, each observation corresponds to a "cell" of children born in a given cohort, from a given CZ, and with parent's income in a given percentile within the $\mathrm{CZ}$. The components of the final data set are briefly described below; more detail can be found in Appendix B. Expenditures, revenues, and income are converted to 2000 US dollars.

School Expenditures and Revenues and Funding Formula Components My instrumental variables approach relies on simulating district revenues using states' funding formulas. This procedure requires information not only on total revenues, but also on all the variables entering the formula (such as property values, enrollment, household income, tax rates, etc.). Both the nature of these elements and the way they are measured vary across states. This information is therefore not readily available from a unique source. ${ }^{10}$

To address this data limitation I construct a novel district-level panel dataset for each state, drawing from states' detailed historical records on school finance accessed through a series of FOIA requests. Each dataset contains all the elements of the funding formula in place in each year in a given state, as well as total expenditures and revenues. I was able to construct these datasets for 20 states, comprising $405 \mathrm{CZs}$ and 8,102 school districts and including approximately 62 percent of all students in the country. These 20 states, highlighted in Figure AII, appear similar to the remaining states with respect to a range of characteristics of schools, families, and households (Table AI). ${ }^{11}$ The elements of the dataset for each state are described in Table CI, and the various formulas are described in detail in Appendix D. ${ }^{12}$

\footnotetext{
${ }^{10}$ Information on school districts' expenditures and revenues is available from the US Census of Government and the National Center for Education Statistics (NCES) Longitudinal School District Dataset.

${ }^{11}$ The only statistically different differences are population size and the divorce rate.

${ }^{12}$ I obtained the data via direct requests or through FOIA requests addressed to each state's Department of Education. The request was fulfilled by the states of California (data available for the years 1996-2004), Colorado (1994-2004), Florida (1988-2004), Georgia (1987-2004), Illinois (1987-2004), Kentucky (1991-2004), Louisiana (19932004), Massachusetts (1993-2004), Michigan (1990-2004), Minnesota (1991-2004), Montana (1994-2004), Nebraska (1993-2004), New Jersey (1988-2004), New York (1986-2004), North Dakota (1986-2004), Ohio (1986-2004), Pennsylvania (1995-2004), Texas (1986-2004), Utah (1986-2004), and Wisconsin (1986-2004). The remaining states did not
} 
Table I (Panel A) summarizes the variation in school revenues across districts within each $\mathrm{CZ}$ or state. While the difference in revenues between the highest-income and the lowestincome district is small on average, it ranges from $-\$ 2,306$ to $\$ 12,965$ across states, and from $-\$ 10,710$ to $\$ 14,518$ across CZs in 1990 .

School Finance Reforms I compile a list of all state-level school finance reforms passed between 1980 and 2004, to encompass the time period when the cohorts at study (born between 1980 and 1986) were in grades one to twelve (i.e., 1986-2004). To do so I combine information from "Public School Finance Programs of the United States and Canada" (1990-1991'13 and 1998-199914) and from Verstegen and Jordan (2009). These publications describe the funding schemes in place at different points in time and include details of the timing and content of each reform. I complement these data with information from Manwaring and Sheffrin (1997), Hoxby (2001), Jackson et al. (2015), and Lafortune et al. (2018). Information is largely consistent across the different sources; when discrepancies are found, priority is given to the "Public School Finance Programs of United States and Canada" for older events and to Lafortune et al. (2018) for more recent ones. Appendix E briefly describes the reforms used in the analysis, and Figures AIII and AIV summarize the timing of these events.

Income I use tabulations of household income at the school district level, taken from the US Census of Population and Housing for the years 1980, 1990, and 2000 and from the American Community Survey for the year 2010, to calculate median household income in each district. ${ }^{15}$ I link these data with information on per pupil school revenues to compute measures of equalization across districts in each state and year.

Intergenerational Mobility I use the intergenerational mobility measure proposed and constructed by Chetty et al. (2014), and defined as children's percentile in the national income maintain detailed records on historical school finance data. California, Illinois, Florida, Georgia, New York, North Dakota, Ohio, Pennsylvania, and Utah did not experience any reform between 1986 and 2004; the remaining states experienced at least one reform, and New Jersey and Texas experienced two reforms. Appendix D describes the formulas in more detail.

${ }^{13}$ Albany, NY : American Education Finance Association and Center for the Study of the States, The Nelson A. Rockefeller Institute of Government, State University of New York, 1992.

${ }^{14}$ Washington, DC: US Dept. of Education, Office of Educational Research and Improvement, National Center for Education Statistics, 2001.

${ }^{15}$ Income tabulations at the school district level are contained in the Census STF3F file for 1980 and published as part of the National Center for Education Statistics' (NCES) School District Demographic System for the years 1990 and 2000. For the year 2010 I use the 2008-2012 district-level tabulations of the American Community Survey provided by the School District Demographic System. 
distribution for a given $\mathrm{CZ}$, cohort, and income percentile of the parents. To construct this measure, Chetty et al. (2014) use administrative tax records to estimate the intercept and slope of the linear relationship between parents' and children's national income percentiles for 637 out of 722 CZs (including 327 CZs for which simulated revenues are available) and for each cohort of children born between 1980 and $1986 .{ }^{16}$ Combined with information on the national and CZ-specific distributions of parental income, these estimates allow me to predict the income percentiles of children for each $\mathrm{CZ}$, cohort, and parental income percentile in the $\mathrm{CZ} .{ }^{17}$ Compared to the simple correlation between parents' and children's incomes (used by Solon, 1992; Björklund and Jäntti, 1997; Lee and Solon, 2009, among others) this measure allows me to study the economic performance of children relative to their parents for different percentiles of parental income. ${ }^{18}$

The final dataset contains children's percentiles for $327 \mathrm{CZs}$, seven birth cohorts, and six CZ-specific parental income percentiles (10th, 25th, 50th, 75th, 90th, and 99th). On average, children with parental income below the national median experience upward mobility, whereas children with parental income above the median experience downward mobility (Table I, Panel B). ${ }^{19}$ Wide differences exist across CZs (Figure AI): The mean percentile of children with parents on the 25th percentile is as low as 32 in Gordon, SD and as high as 61 in Sioux Center, IA, while for children with parents on the 75th percentile it is as low as 51 in Gallup, AZ and as high as 70 in Hiawatha, KS. Mobility appears to increase, albeit slowly, across cohorts. I complement information on income mobility with data on education mobility, also constructed and provided by Chetty et al. (2014) and defined as the probability of being enrolled in college at age 19 for each CZ, birth cohort (1984-1990), and parents' income percentile in the $\mathrm{CZ} \cdot{ }^{20}$

\footnotetext{
${ }^{16}$ Slope and intercept estimates are published as the Online Data Table 1 of Chetty et al. (2014), available at https://opportunityinsights.org/. Children are assigned to CZs based on when they lived at age 16, irrespective of whether they moved when they entered the labor market.

${ }^{17}$ I choose to use parents' percentiles in the $\mathrm{CZ}$, rather than in the national distribution, to account for differences in income distributions across CZs. This allows me to correctly weigh each CZ in the sample; using percentiles in the national distribution instead translates into having observation in the data set that correspond to different counts of people. To see this, consider a CZ with 10 percent of individuals on the 25th national percentile and only 0.1 percent on the 99th percentile. Using national percentiles these two groups would receive equal weight in the estimation, even though the first contains more people than the second. Information on the income distributions within each CZ is published as the Online Data Table 7 of Chetty et al. (2014), available at https://opportunityinsights.org/.

${ }^{18}$ To see this, consider an increase in the parent-child income correlation. Such an increase could be caused by better outcomes for the poor or worse outcomes for the rich. My measure, analogous to Chetty et al. (2014)'s "absolute" mobility, allows me to study these two cases separately.

${ }^{19}$ This result is not mechanical: income ranks of parents and children are defined relative to the national income distribution, whereas intergenerational mobility measures are estimated at the CZ level.

${ }^{20}$ Measures of education mobility are available for cohorts 1984 to 1993 . Since school finance data are only
} 
Cross-County Migration Data on county-level migration flows and on the incomes of migrants are taken from the IRS Statistics of Income (SOI) and cover years 1991 to 2004. I calculate county-level individual migration rates as the ratio between the total number of in-migrants and out-migrants and the county's population.

House Prices To calculate changes in property values I use transaction-based annual house price indexes at the 5-digit zip code level for the years 1986 to 2004, published by the Federal Housing Finance Agency (FHFA). ${ }^{21}$ I use information from the 1990 Census to link zip codes to school districts, and I aggregate house prices at the district level based on the population in each zip code. The coverage of this dataset varies across time, with 48 percent of all zip codes in 1986, 70 percent in 1995, and almost 100 percent in 2004. The available information allows me to obtain a measure of house prices for 64 percent of all districts in 1986, 82 percent in 1995, and 100 percent in 2004.

Other School District Data Additional district-level information from the NCES's Local Education Agency Universe Survey Data includes the number of teachers employed in each district and year, available for the years 1988 to 2010.

\section{Measuring Inequality in School Expenditure}

As a first step in my empirical analysis, I build a measure of inequality in per pupil revenues across school districts. In keeping with the theoretical framework, I measure inequality as the slope of the relationship between per pupil revenues and per capita income across districts within each state, captured by the parameter $\beta_{s t}$ in the following equation: ${ }^{22}$

$$
e_{d t}=\alpha_{s t}+\beta_{s t} x_{d t}+\varepsilon_{d t}
$$

where $e_{d t}$ is per pupil revenue in district $d$ (located in state $s$ ) and year $t, x_{d t}$ is median per capita household income, and $\varepsilon_{d t}$ is an error term.

The parameter $\beta_{s t}$, estimated separately for each state $s$ and year $t$, represents the degree of inequality in school funding across districts. When the funding scheme is unequal and revavailable until 2004, however, I restrict my attention to cohorts until 1990 to have information on funding schemes for at least nine school years for each cohort.

${ }^{21}$ The construction of this index is explained in detail in Bogin et al. (2016).

${ }^{22}$ A similar approach has been used by Hoxby (1998); Card and Payne (2002); Lafortune et al. (2018). 
enues are higher (lower) in richer (poorer) districts, $\beta_{s t}$ will be positive. When the funding scheme is redistributive and revenues are higher in low-income districts, $\beta_{\text {st }}$ will instead be negative. Lastly, when the funding scheme is equalized and revenues are similar across richer and poorer districts, $\beta_{s t}$ will be close to zero. Appendix Figure AV shows the linear relationship between per-pupil revenues and per capita income for school districts in New Jersey and Georgia in 1990 and 2000. In New Jersey, which experienced a school finance equalization reform in 1991, the slope of the relationship (i.e., $\beta_{s t}$ ) decreased in 2000 relative to 1990. In Georgia, which did not experience any reform, the slope remained constant over this decade.

To study the effects of changes in $\beta_{s t}$ (measured at the year level) on intergenerational mobility (measured at the cohort level) I assign each cohort a measure of revenue inequality experienced while in school, constructed as the average $\beta_{s t}$ over the calendar years in which the cohort was in grades one to twelve. ${ }^{23}$ For cohorts born between 1980 and 1986, this requires estimating $\beta_{s t}$ for each state and year between 1986 and 2004. Income data, however, are only available for Census years. To back out median district incomes for intercensal years, I directly exploit the timing of each reform and I impute income values to each district depending on whether the corresponding state had a school finance reform during that decade. If a reform took place, I impute the income of the Census year at the beginning of the decade to the years preceding the reform (including the year of the reform) and the income of the Census year at the end of the decade to the years following the reform. If no reform took place, I interpolate between the income values of the Census years at the beginning and at the end of the decade. ${ }^{24}$ To demonstrate that my results are not driven by this imputation procedure, in robustness checks I use a version of $\beta_{s t}$ estimated assigning the 1990 median district income to all years (Table AVIII).

On average, the parameter $\beta_{s t}$ is equal to 0.019 for states without a school finance reform (with a standard deviation of 0.098); for states with a reform it equals 0.041 in the years before the reform (with a standard deviation of 0.027 ) and -0.004 in the years after the reform (with a standard deviation of 0.034, Table I, Panel C). Figure I illustrates the change in $\beta_{s t}$ in the years surrounding a reform. The figure shows point estimates and 90 percent confidence intervals

\footnotetext{
${ }^{23}$ For example, the $\beta_{s}$ for the 1980 cohort is the average of the $\beta_{s t}$ for the years 1986-1997.

${ }^{24}$ If two reforms take place in one decade (which is the case for Montana, New Jersey, New York, and Oregon), I assign the income of the Census year at the beginning of the decade to the years preceding the first reform, the income of the Census year at the end of the decade to the years following the last reform, and I interpolate between these two values for the years between the two reforms.
} 
of the coefficients $\delta_{k}$ in the following equation:

$$
\hat{\beta}_{s t}=\sum_{k=-3}^{10} \delta_{k} R_{s} \mathbb{1}\left(t-\text { ryear }_{s}=k\right)+\varepsilon_{s t}
$$

where $\hat{\beta}_{s t}$ is the estimated $\beta_{s t}$ coefficient for state $s$ and year $t, R_{s}$ equals 1 if state $s$ experienced a school finance reform between 1986 and 2004, and ryear $r_{s}$ is the year of the first of these reforms. ${ }^{25}$ Estimates of $\beta_{s t}$ decline immediately following a school finance reform and remain stable at this lower level ten years after the reform. Appendix Figure AVI shows estimates of $\beta_{s t}$ separately for "equity" reforms (passed before 1990) and "adequacy" reforms (passed after 1990). The initial drop in $\beta$ after an equity reform is slightly larger than after an adequacy reform. The former, however, tends to revert to its pre-reform values, while the latter remains stable over time.

\section{Endogeneity of Post-Reform School Expenditure and Simulated Instruments}

\subsection{Explaining The Need for An Instrument}

Having estimated a measure $\beta$ for the inequality in school spending, my next goal is to test the theoretical predictions derived in Section 3 and to estimate the effects of a decline in $\beta$ on intergenerational mobility. Doing so requires a source of exogenous variation in $\beta$. School finance reforms are a natural candidate; indeed, several studies have used these reforms as exogenous shifters of school spending to study a variety of children's outcomes (Jackson et al., 2015; Lafortune et al., 2018).

If one is simply interested in the effect of the passage of any school finance reform on students' outcomes (as in Lafortune et al., 2018), the exogeneity in the timing is the only required identifying assumption. If, instead, one wants to estimate the causal effect of the changes in revenues and expenditures triggered by the reform, one must deal with an endogeneity problem. ${ }^{26}$ To see this, consider the following simplified version of equation (5), which expresses mobility of children in $\mathrm{CZ} c$ and state $s$, cohort $b$, and with parents' income rank $r$ as a function

\footnotetext{
${ }^{25}$ The estimation includes years 1986 to 2004 , and standard errors are clustered at the state level.

${ }^{26}$ This is analogous to wanting to estimate a "structural" parameter, whereas Lafortune et al. (2018) estimate the reduced-form effect of equalization reforms.
} 
of $\beta$ :

$$
M_{c b}^{r}=\delta^{r} \beta_{s b}+\theta_{c}+\tau_{b}+\tilde{\varepsilon}_{c b}
$$

The variable $\tilde{\varepsilon}_{c b}$ is a residual component of mobility, which can include the composition of their group of peers and, more generally, of their community, summarized by $\tilde{X}_{b c}$ :

$$
\tilde{\varepsilon}_{c b}=\gamma \tilde{X}_{c b}+\varepsilon_{c b}
$$

To simplify matters, I express the variable $\beta_{s b}$ as the product between the parameters of the funding formula of state $s, g_{s b}$, and the variables entering that formula, $X_{s b}: \beta_{s b}=g_{s b} X_{s b}$ (where $\operatorname{Cov}\left(\tilde{X}_{c b}, X_{s b} \neq 0\right)$ ).

Suppose that, due to a school finance reform, the funding formula for cohort $b+1$ changes to $g_{s b+1}$. Changes to the funding formula affect the tax price (i.e., the dollars of tax revenues required to increase spending by one dollar), which represents the "price" of public schools to taxpayers, and - in turn - households' budget constraints. Households will respond to this change in the tax price by "voting with their feet" (Tiebout, 1956) and by moving to a different district (Aaronson, 1999; Dee, 2000; Figlio and Lucas, 2004; Epple and Ferreyra, 2008; Chakrabarti and Roy, 2015). Due to this sorting, variables such as house prices and property tax revenues, which are included in $X_{s b}$, will change to $X_{s b+1}$. At the same time, this sorting could affect intergenerational mobility through changes in $\tilde{X}_{c b}{ }^{27}$

OLS estimates of $\delta^{r}$ from the first-differenced version of equation (8) are only consistent if the following exclusion restriction holds:

$$
\mathbb{E}\left[\left(g_{s b+1} X_{s b+1}-g_{s b} X_{s b}\right)\left(\gamma \tilde{X}_{c b+1}+\varepsilon_{c b+1}-\gamma \tilde{X}_{c b}-\varepsilon_{c b}\right)\right]=0
$$

Since $\mathbb{E}\left(X_{s b+1} \tilde{X}_{c b+1}\right) \neq 0$, the exclusion restriction fails, giving rise to an endogeneity problem.

How Prevalent Is Household Sorting After A School Finance Reform? The answer to this question determines the importance of addressing the endogeneity problem. To quantify this, I conduct an event study of county-level migration flows around an equalization event. I estimate:

$$
m_{k t}=\sum_{n=-5}^{5} \delta_{n} R_{s(k)} \mathbb{1}\left(t-\text { ryear }_{s(k)}=n\right)+\gamma_{k}+\tau_{t}+\varepsilon_{k t}
$$

\footnotetext{
${ }^{27}$ Note that this is the same justification for the IV strategy of Jackson et al. (2015), who also seek to estimate the causal effect of changes in expenditure levels on student outcomes (as opposed to just the effect of the reform).
} 
where $m_{k t}$ is either the in-migration or the out-migration rate, defined respectively as the total number of households moving in or out of county $k$ in year $t$, divided by the total number of households in $k$. The variable $R_{s(k)}$ equals 1 if state $s$ of county $k$ experienced a school finance reform in the years 1986-2004, and ryear $_{s(k)}$ is the year of the earliest reform. The vectors $\gamma_{k}$ and $\tau_{t}$ are county and year fixed effects, respectively, and $\varepsilon_{k t}$ is an error term. Estimates of the coefficients $\delta_{n}$, shown in Figure III (top panel), capture year-specific changes in migration flows after each reform relative to the year preceding a reform. The differences between inmigration and out-migration rates of counties with and without a reform are indistinguishable from zero in the years leading to a reform, and they increase by 17 and 19 percent (or 0.13 and 0.14 percentage points) respectively in the years following the reform.

These migration patterns, however, cause endogeneity in post-reform expenditure only if they are associated with sorting on income and wealth. To better characterize the patterns of sorting, I re-estimate equation (9) using the absolute value of the percentage difference between the incomes of migrants and stayers as the dependent variable. These estimates, shown in the bottom panel of Figure III, reveal that the absolute difference the average income of both in-migrants and out-migrants and the average income of stayers is flat in the years leading to a reform, and it increases significantly (to a maximum of 9 and 7 percent, or 2.1 and 1.7 percentage points respectively) in the years after the reform.

Taken together, these results provide evidence of significant household sorting across counties following a school finance reform. ${ }^{28}$ This sorting can affect house prices, change the composition of local communities, and in turn lead to the endogeneity of post-reform revenues. ${ }^{29}$

\subsection{Constructing the Simulated Instrument}

I address this endogeneity issue with a simulated-instruments approach (as in Gruber and Saez, 2002) which, similarly to Hyman (2017), directly exploits changes in each state's formula type and parameters generated by a reform. ${ }^{30}$ The goal of this strategy is to isolate the exogenous variation in funding inequality, driven by the timing of the reform and the type of funding

\footnotetext{
${ }^{28}$ Income and wealth are often strongly positively correlated (Wolff and Zacharias, 2009).

${ }^{29}$ This finding is in partial contrast with Lafortune et al. (2018), who analyze changes in the income gap between ex ante richer and poorer districts, as well as changes in the demographic composition of students across districts after each reform, and find no evidence of changes in these variables.

${ }^{30}$ Hyman (2017) focuses on Michigan's 1994 school finance reform and directly uses changes in the foundation grant (the relevant policy parameter for this reform) as an instrument for expenditures. Goldsmith-Pinkham et al. (2018) illustrate how, in a simulated-instruments context, identification leverages variation in the change in the parameters of a given policy. The source of exogenous variation used in my analysis is thus the same as in Hyman (2017), which I expand to include a large sample of US states.
} 
formula, from the endogenous variation driven by sorting and changes in house prices and in the tax base.

It is useful to express the post-reform $\beta_{s b+1}$ as the sum of an exogenous component and an endogenous one:

$$
\beta_{s t+1}=g_{s t+1} X_{s t}+b_{s t+1}, \text { where } b_{s t+1}=g_{s t+1} X_{s t+1}-g_{s t+1} X_{s t}
$$

The quantity $g_{t+1} X_{s t}$ is the $\beta_{s t+1}$ that would have resulted had households not sorted (and house prices not changed). This "simulated" version of $\beta_{s t+1}$, which I denote as $\beta_{s t+1}^{s i m}$, can be used as an instrument to obtain consistent estimates of $\delta^{r}$ in equation (8). The required exclusion restriction becomes:

$$
\mathbb{E}\left[\left(g_{s b+1} X_{s b}-g_{s b} X_{s b}\right)\left(\gamma \tilde{X}_{c b+1}+\varepsilon_{c b+1}-\gamma \tilde{X}_{c b}-\varepsilon_{c b}\right)\right]=0
$$

This condition is satisfied if $g_{s b+1}-g_{s b}$ is unrelated to $X_{c b+1}-X_{c b}$ or, in other words, if the specific change in the funding formula is unrelated to sorting and the subsequent changes in house prices. I provide evidence in favor of this assumption in Appendix Table AII, which I describe below.

The correlation between $b_{s t+1}$ and intergenerational mobility determines the sign of the bias of the OLS estimates. If the effect of $\beta$ on mobility is negative, a positive correlation implies that OLS will be biased toward zero, whereas a negative correlation implies that OLS will overstate the negative effect of $\beta$ on mobility. The sign of this correlation is uncertain $e x$ ante and depends on both $X_{s t}$ and $g_{s t+1}$.

\subsubsection{The Importance of Accounting for Differences in Funding Formulas Across States}

While earlier studies of school finance reforms (such as Card and Payne, 2002) have not explicitly accounted for the endogeneity in post-reform revenues, more recent studies (such as Jackson et al., 2015; Hyman, 2017) have recognized and addressed it. Jackson et al. (2015) (JJP hereafter), for example, study the effects of several reforms passed across all US states since the 1970s and instrument expenditure using the timing of each reform, districts' initial position in the state's expenditure and income distributions, and the type of funding plan (e.g. foundation plan, or equalized effort).

While similar to JJP's, my approach bears one important difference. Their strategy relies 
on the assumption that all reforms of the same type had the same effect on expenditure, conditional on a district's initial position in the state's expenditure and income distributions. If one were to apply JJP's strategy in my context, the instrument would be specified as $\hat{\beta}_{s t+1}^{s i m}=\hat{g} \hat{X}_{s t}{ }^{31}$ In other words, the instrument formula would be the same across all states, and the set of characteristics considered $\left(\hat{X}_{s t}\right)$ would be a subset of all the ones entering the actual formula.

What happens when one uses $\hat{\beta}_{s t+1}^{\text {sim }}$ in lieu of $\beta_{s t+1}^{s i m}$ as an instrument? First, the formula $\hat{g}$ can be seen as a "restricted" or simplified version of $g_{s t+1}$; as a result, using $\hat{g}$ implies using fewer instruments than there are available, which could lead to asymptotic inefficiency (Greene, 2008, Chapter 12). ${ }^{32}$

Second, in the presence of large differences in $g_{s t}$ across states, the standard IV monotonicity assumption (Angrist and Imbens, 1995; Angrist et al., 1996) is more likely to be violated when using $\hat{\beta}_{s t}^{\text {sim }}$ than when using $\beta_{s t}^{\text {sim }}$. To see this, suppose I have an endogenous $\beta_{s t+1}=g_{s t+1} X_{s t+1}$ with a corresponding value of JJP's instrument $\hat{\beta}_{s t+1}^{s i m}=\hat{g} \hat{X}_{s t}$. Suppose now that all states' formulas change to $g_{k t+1}^{\prime} \forall k$, such that the resulting instrument for state $s$ would be $\hat{\beta}_{s t+1}^{s i m}=\hat{g}^{\prime} \hat{X}_{s t} \leq \hat{\beta}_{s t+1}^{s i m}$. Monotonicity requires that $\beta_{s t+1}^{\prime}=g_{s t+1}^{\prime} X_{s t+1} \leq \beta_{s t+1}$ for all $s$; this condition would be violated if there is a state where the instrument predicts an increase in equalization, but the actual changes in the formula and in $X_{s t}$ lead to a decline in equalization (or vice versa). If instead one uses an instrument $\beta_{s t+1}^{s i m}=g_{s t+1} X_{s t}$, this assumption would be violated only if the endogenous change in $X_{s t}$ alone were so dramatic to yield a change in $\beta_{s t+1}$ of the opposite sign as the the change in $\beta_{s t+1}^{s i m}$, since the function $g_{s t+1}^{\prime}$ is the same in both $\beta_{s t+1}$ and $\beta_{s t+1}^{s i m} .33$

Clearly, the extent to which $\beta_{s t}^{\text {sim }}$ will be a better instrument than $\hat{\beta}_{s t}^{\text {sim }}$ depends on how large the heterogeneity in funding formula changes across states is in reality (Hoxby, 2001). Figure II shows the trend in $\beta$ around the year of the reform in five states with reforms between 1989 and 1996. While some reforms were effective in reducing $\beta$ (such as the one in Wisconsin in 1996, which reduced it from 0.021 in the year before the reform to 0.003 four years after the reform), some others were considerably less effective (such as the one in Michigan, which only

\footnotetext{
${ }^{31}$ Note that Jackson et al. (2015) instrument expenditure and not $\beta$.

${ }^{32}$ Goldsmith-Pinkham et al. (2018) explain how, in a simulated instrument context, the parameters of the formula used to construct the instrument represent the actual instruments. Therefore, using a simplified version of the formula implies using fewer-than-available parameters.

${ }^{33}$ Mogstad et al. (2019) explain how, in the context of 2SLS with many instruments, the validity of the strategy is guaranteed by a (milder) "partial" monotonicity assumption, which essentially requires the standard monotonicity assumption to apply individually to each instrument. The reasoning outlined in the text still applies: when using $\beta_{s t+1}^{s i m}$, the instruments are the actual parameters of the funding formula entering $\beta_{s t+1}$, whereas when using $\hat{\beta}_{s t+1}^{s i m}$ they are not.
} 
reduced $\beta$ from 0.045 to 0.041$).{ }^{34}$

Different reforms also had different effects on house prices. Figure IV shows trends in the difference in house prices between districts with household income above and below the state median in 1990. While some reforms (such as the one of Texas) were followed by a decline in this difference (which implies an increase in house prices in poorer districts relative to richer ones), others (such as Michigan) did not trigger any significant changes, and others (such as Massachusetts) were followed by an increase. ${ }^{35}$

These differences in the effectiveness of each reform and in the house price responses across states suggest that the use of $\beta_{s t}^{\text {sim }}$ in lieu of $\hat{\beta}_{s t}^{\text {sim }}$ could significantly improve both the consistency and the efficiency of the estimates. In Section 7, I contrast estimates obtained using $\beta_{s t}^{s i m}$ with those obtained using $\hat{\beta}_{s t}^{s i m}$, and show that the differences in these two sets of estimates are significant.

Implementation I construct $\beta^{\text {sim }}$ as follows. First, I obtain the funding formulas in place in each school district and year. These formulas express total and per pupil revenues as a function of district-specific characteristics (such as enrollment, property tax rates, property values, and average gross income) and parameters set by state laws. I construct each formula using information from "Public School Finance Programs of United States and Canada" (19901991 and 1998-1999), as well as various state legislative bills (see Appendix D for details on each specific formula). I then use the formulas to simulate each district's post-reform revenues, holding endogenous characteristics (i.e., property values, property tax rates, and income) fixed at their pre-reform values. ${ }^{36}$ Lastly, I construct $\beta^{\text {sim }}$ for each state and year, estimating equation (6) using simulated revenues in lieu of actual revenues. ${ }^{37}$

\footnotetext{
${ }^{34}$ These differences are consistent with the fact that Jackson et al. (2015) find that, on average, school finance reforms increase expenditure more in ex ante lower-spending districts, Hyman (2017) finds that Michigan's Proposal A increased expenditure more in low-poverty districts.

${ }^{35}$ Each point and spike in Figure IV represent the estimate and the 90 percent confidence interval of the coefficients $\delta_{n}$ in the regression $H P_{d t}=\sum_{n=-4}^{6} \delta_{n} 1\left(\right.$ Income $_{d, 1990}>$ Median $\left._{s}\right) R_{s(d)} 1\left(t-\right.$ Ryear $\left._{s(d)}=n\right)+\theta_{d}+\tau_{t}+\varepsilon_{d t}$, where $H P_{d t}$ is the house price index of district $d$ in year $t$, Income $e_{d, 1990}$ is average household income of district $d$ in 1990, Median $s$ is median household income in state $s$ in 1990, $R_{s(d)}$ equals 1 if state $s$ where the district is located experienced a school finance reform in the years 1986-2004, Ryear ${ }_{s(d)}$ is the year of the earliest reform, and $\theta_{d}$ and $\tau_{t}$ are district and year fixed effects. The parameters are estimated separately for each state. Observations are weighted by population. Standard errors are clustered at the state level.

${ }^{36} \mathrm{I}$ adjust property values using the FHFA's US All Transactions Index (quarterly data, available at https://www.fhfa.gov/DataTools/Downloads/Pages/House-Price-Index-Datasets.aspx) to account for nationwide changes in house prices, and I correct for inflation using the CPI.

${ }^{37}$ For states with no reform between 1986 and 2004, I simply set $\beta=\beta^{s}$ for all years and cohorts.
} 
Assumptions The validity of this approach relies on the exogeneity of the timing of each reform and of the type and parameters of the funding formula. This assumption could be violated if the funding formula chosen by each state or the timing of the reform were related to the state's socioeconomic or political conditions. Hoxby (2001), however, explains that equalization schemes are more likely to be a reflection of a particular legal rhetoric rather than of specific objectives in terms of school spending and redistribution. This would explain why some of these reforms have had smaller-than-intended effects. In addition, the timing of a reform often depends on the length of a legislative process or on the timing of a court ruling. This suggests that both the timing and the type of reforms can be plausibly considered random.

Figure V shows trends in simulated and actual revenues in some of the largest states, separately for districts in the top and bottom quartile of the state's initial distribution of per pupil expenditure. The extent to which actual revenues differ from simulated revenues varies across states; it depends on the changes in property values in each district following a reform, driven by the ex ante characteristics of the district and by the change in the funding formulas. Districts where a reform triggered an increase in house prices experienced higher revenues than they would have had house prices not changed, and vice versa (Figure AVII). ${ }^{38}$

On average, the parameter $\beta^{\text {sim }}$ equals 0.040 (with a standard deviation of 0.030 ) in the years preceding each reform, and it drops to 0.003 (with a standard deviation of 0.031) in the years after the reform (Table I, Panel C). Estimates from the first stage of the IV estimation reveal that $\beta^{s i m}$ is a strong predictor for $\beta$; the Kleibergen-Paap Wald F-statistic of the first stage (Stock and Yogo, 2002), shown in Table III, is around 20. The instrument is also uncorrelated with changes in house prices, migration rates, and differences in the incomes of migrants and incumbents, which are precisely the sources of the endogeneity that the instrument is supposed to address (Table AII). ${ }^{39}$

\section{Effects of Equalization on Intergenerational Mobility}

Having constructed a measure for the inequality in school spending and an instrument for it, I now turn my attention to estimating the effects of spending equalization on children's

\footnotetext{
${ }^{38}$ Figure AVII shows the relationship between the percentage change in house prices after a reform and the difference between actual and simulated revenues.

${ }^{39}$ The table shows estimates of a regression of $\beta_{s t}^{s i m}$ on the average change in house prices, the average inmigration and out-migration rate, and the ratios between the incomes of in-migrants and out-migrants and the incomes of stayers, as well as state and year fixed effects. Observations are at the state and year level. These estimates indicate that none of these variables predict the change in $\beta_{s t}^{s i m}$ over time.
} 
intergenerational mobility. The identification of these effects exploits variation in exposure to equalization across cohorts and states, given by exogenous differences in the timing and effectiveness of the reforms.

To better illustrate identification, Figure VI shows an event study of intergenerational mobility, measured as the average income rank of children with parental incomes in the 25th percentile, by exposure to a reform and separately for states with an "effective" school finance reform (i.e. one that resulted in a negative post-reform $\beta$ or a decline in $\beta$ of at least 50 percent, solid line) and for those with an "ineffective" reform (dashed line), using states with no reform as a control group. Similarly to JJP, exposure to a reform counts the number of school years a given cohort in a given state was exposed to a "post-reform" school finance regime: Exposure $=$ birth year $+18-$ (reform year +1 ) (exposure is weakly negative for non-exposed cohorts). To better understand this measure, consider the 1980 cohort in Massachusetts, where a school finance reform was passed in 1994. This cohort, in school from 1986 to 1997, was exposed to a "post-reform" regime for $1980+18-(1994+1)=3$ years, namely 1995, 1996, and 1997.

The figure shows that, in states with an effective reform, mobility gradually increases with exposure (e.g. it is 3.3 percentiles higher for cohorts exposed for twelve years compared with non-exposed cohorts). In states with an ineffective reform, on the other hand, mobility - if anything - declines with exposure. ${ }^{40}$ Importantly, the figure shows the absence of any trends in mobility for non-exposed cohorts, which supports the assumption of exogenous timing of each reform. Taken together, these estimates provide a first piece of evidence that exposure to effective reforms is associated with increased intergenerational mobility.

\subsection{OLS Estimates}

While useful to illustrate the trends in intergenerational mobility across cohorts and states, the evidence in Figure VI is based on an arbitrary definition of the effectiveness of a reform; in addition, it only informs us on the mobility of children whose parents are at the bottom of the income distribution. To more rigorously test the effect of a change in $\beta$ on intergenerational

\footnotetext{
${ }^{40}$ The figure shows OLS points estimates and 90 percent confidence intervals of the coefficients $\delta_{n}$ in the equation $m_{c b}=\sum_{n=-6}^{12} \delta_{n} E_{n(s b)}+\theta_{c}+\tau_{b}+\varepsilon_{c b}$, where $m_{c b}$ is the mean rank of children in CZ $c$, cohort $b$, and with parents' income in the 25th percentile in the national income distribution, $E_{n}$ equals one if cohort $b$ in state $s$ was exposed to a post-school finance reform regime for $n$ years $\left(E_{n}=b+18-\left(\right.\right.$ ryear $\left._{s}+1\right)$, and ryear $r_{s}$ is the year of the first school finance reform in state $s$ between 1980 and 2004), and the vectors $\theta_{c}$ and $\tau_{b}$ contain $C Z$ and cohort fixed effects. The coefficients are estimated separately for states with effective and ineffective reforms, using states with no reform as a control group. Observations are weighted by the number of children in each $\mathrm{CZ}$ and cohort. Standard errors are clustered at the state and birth cohort level.
} 
mobility and to explore its effects on children with different parental incomes, I estimate the following equation:

$$
M_{c b x}=\delta_{0} \hat{\beta}_{s(c) b}+\delta \hat{\beta}_{s(c) b} \times \theta_{n(c x)}+\kappa_{c}+\tau_{b}+\theta_{n(c x)}+\omega_{c b x}
$$

where the variable $M_{c b x}$ is the expected income percentile of children in $\mathrm{CZ} c$, cohort $b$, and with parental income in the $x$-th percentile in the CZ (either the 10th, 25th, 50th, 75th, 90th, or 99th). ${ }^{41}$ The variable $\hat{\beta}_{s(c) b}$ is the estimated state and cohort-specific measure of equalization described in the previous section $(s(c)$ denotes the state where $\mathrm{CZ} c$ is located). $\mathrm{CZ}$ fixed effects $\kappa_{c}$ control for CZ-specific, time-invariant determinants of mobility, and cohort fixed effects $\tau_{b}$ control for secular trends in mobility. The vector $\theta_{n(c x)}$ controls for parents' rank in the national income distribution $n(c x)$, to account for the fact that different CZs might have different income distributions. ${ }^{42}$ The variable $\omega_{c b x}$ is an error term.

In this model the parameter $\delta_{0}$ captures the effect of an increase in $\beta$, i.e., a decline in equalization, on the income percentile of children with the lowest-ranked parental income in the national distribution. The parameter $\delta$ measures instead how much this effect changes as the parental income rank increases. I standardize $\hat{\beta}_{s b}$ across all CZs and cohorts, and I cluster standard errors at the level of the state and the year using a two-way procedure (Cameron and Miller, 2015; Abadie et al., 2017), to account for the fact that $\beta_{s(c) t}$ varies at the state level and to allow for spatial correlation in mobility. For ease of interpretation, I describe my estimates in terms of a reduction in $\beta$, i.e., an increase in equalization.

OLS estimates of equation (10) are shown in Table II. A one-standard deviation reduction in $\beta$, equivalent to a $\$ 4,500$ reduction in the gap in per pupil revenues between the richest and the poorer districts in a state, is associated with a 3.8 percentile increase in mobility of children with parental income at the bottom of the income distribution, although this coefficient is indistinguishable from zero (estimate of $\beta$ equal to -3.8397, Table II, column 1, p-value equal to 0.12 ). An estimate of $\delta$ equal to 0.0246 indicates that this positive association is reduced by 0.025 percentiles with each additional percentile of parental income (estimate of $\beta \times$ parent centile, Table II, column 1, significant at 1 percent). This implies that the same reduction in $\beta$ is associated with a 3.6 percentile increase in mobility for children with parental income in

\footnotetext{
${ }^{41}$ One observation corresponds to a birth cohort, $\mathrm{CZ}$, and percentile of parental income in the CZ.

${ }^{42}$ For example, the 25th CZ-specific percentile in Cleveland, MS corresponds to an income of $\$ 15,000$ and a 10 th percentile in the national distribution; the same CZ-specific percentile in Sheboygan, WI corresponds to an income of $\$ 52,500$ and a 45 th percentile in the national distribution.
} 
the 10th percentile (p-value equal to 0.15 ), a 3.2 percentile increase for children with parental income in the 25th percentile (p-value equal to 0.18 ), and a smaller 1.6 percentile increase for children with parental income in the 90th percentile ( $\mathrm{p}$-value equal to 0.48 ). These estimates are robust to controlling for state fixed effects (Table II, column 2).

In Figure VII (solid line), I relax the linearity restriction of equation (10) and I allow the effect of a decline in $\beta$ to vary flexibly by decile of parental income. These estimates reveal that the relationship between the effect of a decline in $\beta$ and parents' rank in the national income distribution is close to linear. Controlling for $\mathrm{CZ}$ fixed effects, a one-standard-deviation reduction in $\beta$ is associated with a 3.1 percentile increase in mobility for children with parents in the first decile ( $\mathrm{p}$-value equal to 0.15 ), a 3.6 percentile increase for children with parents in the second decile ( $\mathrm{p}$-value equal to 0.16 ), and only a 1.34 percentile increase for children with parents in the top decile ( $\mathrm{p}$-value equal to 0.56 ).

\subsection{Two-Stages Least Squares Estimates}

Household sorting after each school finance reform directly affects both $\beta$ and intergenerational mobility: OLS estimates will therefore be biased and cannot be interpreted as causal. To get at the causal effects, in Table IV I re-estimate the specifications in Table II via 2SLS, using $\hat{\beta}_{s(c) b}^{s i m}$ (as defined in Section 6) and $\hat{\beta}_{s(c) b}^{s i m} \times \theta_{n(x c)}$ as instruments for $\hat{\beta}_{s(c) b}$ and $\hat{\beta}_{s(c) b} \times \theta_{n(x c)}$. Estimates of the first-stage equations, shown in Table III, indicate that $\hat{\beta}_{s(c) b}^{s i m}$ is a strong instrument for $\hat{\beta}_{s(c) b}$ : the Kleibergen-Paap Wald F-statistics are all close to $20 .{ }^{43}$

2SLS estimates confirm the positive relationship between equalization and mobility, but yield larger effects. Controlling for $\mathrm{CZ}$ fixed effects, a one-standard deviation reduction in $\beta$ leads to a 5.8 percentile increase in mobility for children with parental income at the bottom of the national distribution (estimate of $\beta$ equal to -5.8120 , Table IV, column 1 , significant at 10 percent). A positive estimate for $\delta$ ( $\beta \times$ parent centile, significant at 1 percent $)$ indicates that this effect decreases by 0.026 percentiles with each additional percentile of parental income. These estimates translate into a 5.6 and 5.2 percentile increase for children with parental income in the 10th and 25th percentiles (p-values 0.097 and 0.117 ) respectively, but only an insignificant 3.5 percentile increase for those with parents in the 90th percentile ( $\mathrm{p}$-value 0.256). These results also indicate that the average reform, which decreases $\beta$ by approximately 0.64 standard

\footnotetext{
${ }^{43}$ This value is above the critical threshold of 7.03 proposed by Stock and Yogo (2002) for a test with two endogenous variables, two instruments, and a test size equal to 0.10 .
} 
deviations, would increase mobility of children from families in the 10th percentile by 3.6 percentiles and close 13 percent of the gap between the lowest-mobility CZ (Clarksdale, MS) and the highest-mobility CZ (Sioux Center, IA).

As explained by Hoxby (2001), different reforms had different effects on overall school spending in each state: some ended up increasing it, some reduced it. These changes could have a direct effect on intergenerational mobility, above and beyond the change in spending inequality captured by $\beta$ (this effect can be seen in equation (5) through the variable $K_{s}$ ). To account for these changes, in columns 3 and 4 of Table IV I control for average per pupil expenditure in state $s$ on cohort $c\left(e_{s b}\right)$. These estimates reveal that an increase in $e_{s b}$ has a positive, yet small and statistically insignificant effect on mobility. Importantly, the estimates of $\delta_{0}$ and $\delta$ are robust to controlling for $e_{s b}$. These estimates highlight once more the importance of studying changes in revenues and expenditures equalization, as opposed to levels, when the outcome of interest is children's intergenerational mobility.

Estimates are slightly smaller when controlling for state fixed effects (Table IV, column 2). Importantly, in all these specifications 2SLS estimates are approximately 50 percent larger than OLS. This indicates that failure to account for the endogeneity of $\beta$ would lead to severely underestimating the effects of equalization.

In Figure VII (dashed line) I estimate the effects of a decline in $\beta$ separately for each decile of parental income in the national distribution. The patterns of the estimates across the distribution of parental income resemble OLS, but the magnitudes are larger. A one-standard deviation reduction in $\beta$ leads to a 5.4 percentile increase in mobility for children with parental income in the first decile (significant at 10 percent), but only 3.3 percentiles for children with parental income in the top decile (p-value equal to 0.28 ).

Effects on Income To better quantify the magnitude of these effects in monetary terms, I use the national distribution of children's income to map intergenerational mobility measures by $\mathrm{CZ}$, cohort, and parental income percentile into income levels, and I use the logarithm of children's income (conditional on parents' income rank) as the dependent variable in equation (10). 2SLS estimates, shown in column 3 of Table V, indicate that a one-standard deviation reduction in $\beta$ leads to a 17 percent increase in income for children of parents at the bottom of the income distribution (with an estimate of $\beta$ equal to -0.1574 , and $\exp (0.1574)-1=0.17$, Table $\mathrm{V}$, column 3, significant at 10 percent). This effect declines by less than 0.1 percent with each 
additional percentile of parents' income (estimate of $\beta \times$ parent centile equal to 0.0007 , Table $\mathrm{V}$, column 3 , significant at 1 percent). This implies that a one-standard-deviation reduction in $\beta$ leads to a 16.2 percent increase in income for children with parental income in the 10th percentile (p-value 0.095), a 14.9 percent increase for children with parental income in the 25th percentile ( $\mathrm{p}$-value equal to 0.115), and a smaller and insignificant 9.5 percent increase for children with parental income in the 90th percentile ( $\mathrm{p}$-value equal to 0.27). Estimates are robust to controlling for state fixed effects (Table V, column 4).

Reduced-Form Estimates While useful to capture the causal effects of equalization on mobility, 2SLS estimates might be difficult to use for policy purposes: Since households can sort after a reform, policy-makers do not have direct control on $\beta$, but only on $\beta^{\text {sim }}$ though changes in the formula type and parameters. To obtain estimates that can more easily inform public policies, in columns 5 and 6 of Table IV I estimate the reduced-form effect of $\beta^{\text {sim }}$ on intergenerational mobility. These estimates indicate that a one-standard deviation decline in $\beta^{\text {sim }}$ leads to a 4.44 percentile increase in the income rank of children with parents in the 10th percentile (significant at 5 percent). This positive and large estimate implies that a reform which - absent household responses - is effective at equalizing revenues across districts can have significant effects on children's mobility.

Estimates Using Jackson, Johnson, and Persico's (2015) IV Approaches In Table AIV I reestimate equation (10) instrumenting $\beta$ with the slope coefficient of equation (6) obtained using JJP's instruments for expenditure (Jackson et al., 2015, approaches 1 and 2, pages 171-179; I explain the procedure in more depth in Appendix C). ${ }^{44}$ These estimates reveal smaller and imprecise effects of equalization on intergenerational mobility. The significant differences with my 2SLS estimates indicate that failing to account for heterogeneity in funding formulas across states could generate biased estimates of the effects of equalization.

\subsubsection{Heterogeneous Effects of Equalization by School Grade}

The effects of school finance equalization could differ depending on whether equalization happens earlier or later during a child's education path. On one hand, a large literature has established that education investments made at earlier ages yield higher returns (see Cunha and Heckman, 2010, for a review). On the other hand, equalization could be beneficial during high

\footnotetext{
${ }^{44}$ The first stage estimates are shown in Table AIII.
} 
school if it facilitates the transition to college for lower-income children, as college attendance is an important engine for mobility (Rothstein, 2019).

To explore this potential heterogeneity, I estimate the effects of a decline in $\beta$ separately for cohorts in states with a reform during elementary, middle, and high school. I augment equation (10) as follows:

$$
\begin{aligned}
M_{c b x}= & \delta_{0} \hat{\beta}_{s(c) b}+\delta \hat{\beta}_{s(c) b} \times \theta_{n(x c)}+\delta_{0}^{e} \mathrm{El}_{s(c) b} \times \hat{\beta}_{s(c) b}+\delta^{e} \mathrm{El}_{s(c) b} \times \hat{\beta}_{s(c) b} \times \theta_{n(x c)} \\
& +\eta^{m} \operatorname{Mid}_{s(c) b}+\delta_{0}^{m} \operatorname{Mid}_{s(c) b} \times \hat{\beta}_{s(c) b}+\delta^{m} \operatorname{Mid}_{s(c) b} \times \hat{\beta}_{s(c) b} \times \theta_{n(x c)} \\
& +\eta^{h s} \mathrm{HS}_{s(c) b}+\delta_{0}^{h s} \mathrm{HS}_{s(c) b} \times \hat{\beta}_{s(c) b}+\delta^{h s} \mathrm{HS}_{s(c) b} \times \hat{\beta}_{s(c) b} \times \theta_{n(x c)}+\kappa_{c}+\tau_{b}+\theta_{n(x c)}+\omega_{c b x}
\end{aligned}
$$

where $\mathrm{El}_{s(c) b}, \mathrm{Mid}_{s(c) b}$, and $\mathrm{HS}_{s(c) b}$ equal one if cohort $b$ in state $s$ experienced a reform during elementary school (grades 1-5), middle school (grades 6-8), or high school (grades 9-12), respectively. In this specification, the parameters $\delta_{0}^{e}, \delta_{0}^{m}$, and $\delta_{0}^{h s}$ represent the additional effect of a one-standard-deviation increase in $\beta$ on the income percentile of children with the lowestranked parental income, for cohorts in states where a reform hit during elementary, middle, and high school, respectively, and relative to cohorts and states without a reform. The parameters $\delta^{e}, \delta^{m}$, and $\delta^{h s}$ measure instead how much these effects vary as parents' income ranks increase.

2SLS estimates of equation (11) indicate that a decline in $\beta$ is most effective when the reform happens during elementary school, relative to middle and high school. Controlling for CZ fixed effects, a one-standard deviation reduction in $\beta$ leads to an additional 8.5 percentile increase in the income rank of children with parents at the bottom of the income distribution for cohorts with a reform during elementary school, relative to those with no reform (with an estimate of $\beta \times$ reform in elementary school equal to -8.458 , Table VI, column 3 , significant at 10 percent). This effect declines by 0.09 percentiles with each additional percentile of parents' income (estimate of $\beta \times$ parent centile $\times$ reform in elementary school equal to 0.0859 , Table VI, column 3 , significant at 1 percent). These estimates imply that, when a reform hits during elementary school, a reduction in $\beta$ leads to an additional 7.6 percentile and 6.3 percentile higher in mobility for children with parental income in the 10th and 25th percentiles, respectively, with no significant difference for children with parents in the 90th percentile.

By comparison, a one-standard-deviation decline in $\beta$ leads to a smaller 4.4 and 4.2 additional percentiles in the income rank of children with parents at the bottom of the income 
distribution if the reform hits during middle or high school, respectively (with an estimate of $\beta \times$ reform in middle school equal to -4.412 and of $\beta \times$ reform in high school equal to -4.296 , Table VI, column 3, p-values equal to 0.19 and 0.24 ). These effects decline by 0.02 percentiles with each additional percentile of parents' income (estimate of $\beta \times$ parent centile $\times$ reform in middle school equal to 0.024 and of $\beta \times$ parent centile $\times$ reform in high school equal to 0.019 , Table VI, column 3, significant at 10 and 5 percent, respectively). This implies that a reduction in $\beta$ for these cohorts leads to a 4.1 percentile, 3.8 percentile, and 2.5 percentile increase in mobility for children with parental income in the 10th, 25th, and 90th percentiles. All these estimates are robust to controlling for state fixed effects (Table VI, column 4); OLS estimates, shown in columns 1 and 3 of Table VI, are smaller in magnitude but indicate similar patterns.

Consistently with the literature on early childhood investments, these estimates indicate that equalization in school resources is most effective when experienced earlier in a child's education career. Once more, the differences between OLS and 2SLS estimates highlights the importance of accounting for the endogeneity in post-reform revenues.

\subsubsection{Equalization and Income Inequality}

The results presented so far indicate that a decline in $\beta$ has a positive effect on intergenerational mobility, especially for children from low-income families. Intuitively, equalization in school spending closes the gap in investments on the education of low- and high-income students, and this promotes equalization in their later-life outcomes.

The positive average effects of equalization could, however, mask important differences across CZs depending on how income is distributed across school districts. To see this, consider two CZs in the same state, each containing only two districts. The first has one district with per capita income equal to $\$ 25,000$ and per pupil expenditure equal to $\$ 7,000$ and one district with income equal to $\$ 75,000$ and expenditure equal to $\$ 9,000$. The second has one district with income equal to $\$ 15,000$ and expenditure equal to $\$ 5,500$ and one district with income equal to $\$ 85,000$ and expenditure equal to $\$ 8,300$. Both $C Z$ s have an estimated $\beta$ equal to $0.23 .{ }^{45}$ Due to a more unequal income distribution, however, children in the lowest-spending district in the second $\mathrm{CZ}$ will receive $\$ 2,800$ less compared with children in the highest-spending district (or 34 percent). Children in the lowest-spending district in the first $\mathrm{CZ}$, which has a more equal income distribution, will receive only $\$ 2,000$ less compared with children in the highest-

\footnotetext{
${ }^{45} \beta=\frac{9,000-7,000}{75,000-25,000}=\frac{8,300-5,500}{85,000-15,000}=0.04$.
} 
spending district (or 29 percent). The same reduction in $\beta$ could therefore have very different implications in these two CZs.

To investigate the heterogeneity in the effects of equalization across CZs with different income inequality, I re-estimate equation (10) separately for CZs above and below the national median level of inequality, measured as the percentage difference in per capita income between the richest and the poorest district. ${ }^{46}$ Estimates of $\delta_{0}$ and $\delta$ indicate that a decline in $\beta$ has smaller effects in $\mathrm{CZs}$ with income differences in the bottom 25 percent of the cross-CZ distribution ("Low inequality," Table VII, columns 1 and 2) relative to CZs in the top 25 percent ("High inequality," columns 3 and 4). Controlling for CZ fixed effects, a one-standard deviation decline in $\beta$ in "Low inequality" CZs leads to a 4.6, 4.2, and 2.4 percentile increase for children with parents in the 10th, 25th, and 90th percentile respectively (with an estimate of $\beta$ equal to -4.8634 and of $\beta \times$ parent centile equal to 0.0269 , Table VII, column 1, p-values equal to 0.19 and 0.02). These effects are instead larger in "High inequality" CZs: The same decline in $\beta$ leads to a $6.2,5.8$, and 4.4 percentile increase for children with parents in the 10 th, 25 th, and 90th percentile respectively (with an estimate of $\beta$ equal to -6.3731 and of $\beta \times$ parent centile equal to 0.0221 , Table VII, column 3, significant at 10 and 1 percent respectively). Estimates are robust to controlling for state fixed effects (Table VII, column 4 ). ${ }^{47}$

\subsubsection{Equalization and Income Segregation}

The effects of a decline in $\beta$ could also vary according to the degree of income segregation across districts within each CZ. When segregation is high, children from low-income families are more likely to be living and attending school in the same district and, in turn, more likely to benefit from the relative increase in school expenditure following a school finance reform.

To test this hypothesis, I re-estimate equation (10) separately for CZs above and below the national median level of income segregation, measured using the Theil index of districts' 1990 income within each CZ. ${ }^{48}$ Estimates of $\delta_{0}$ and $\delta$ indicate that, controlling for CZ fixed effects, a one-standard deviation decline in $\beta$ in "Low segregation" CZs leads to a 5.2, 4.8, and 3.2 percentile increase for children with parents in the 10th, 25th, and 90th percentile respectively (with an estimate of $\beta$ equal to -5.4864 and of $\beta \times$ parent centile equal to 0.0253 , Table VII, column

\footnotetext{
${ }^{46}$ I calculate this difference using incomes from 1990.

${ }^{47}$ OLS estimates are shown in Table AV.

${ }^{48}$ The Theil index is calculated as $T_{c}=\frac{1}{N} \sum_{i \in c} \frac{y_{i}}{\bar{y}} \ln \frac{y_{i}}{\bar{y}_{c}}$, where $i$ denotes a district, $c$ denotes a CZ, $y_{i}$ is a district's income, and $\bar{y}_{c}$ is median income in the $\mathrm{CZ}$.
} 
1, significant at 10 and 1 percent). Equalization is slightly more effective in CZs with high income segregation: The same decline in $\beta$ leads to a 5.8, 5.5, and 3.9 percentile increase for children with parents in the 10th, 25th, and 90th percentiles, respectively (with an estimate of $\beta$ equal to -6.0725 and of $\beta \times$ parent centile equal to 0.0237 , Table VIII, column 3, p-values equal to 0.11 and 0.001 , respectively). Estimates are robust to controlling for state fixed effects (Table VIII, columns 2 and 4$){ }^{49}$

Taken together, these results suggest that the effectiveness of an equalization reform depends on the geographic distribution of income. This heterogeneity could have important implications for the design of school finance plans.

\subsection{Robustness}

Estimating $\beta$ Without Income Interpolation The above estimates are obtained imputing income for intercensal years, using the procedure outlined in Section 5. To check that results are not dependent on this imputation procedure, in Table AVIII I re-estimate the main specifications with a version of $\beta$ estimated using income data from 1990 for all years. These estimates are similar to those in Table IV, indicating that the main results are not driven by this imputation procedure.

CZs Without a State Border Out of 327 CZs included in the analysis, 53 are crossed by one or more state borders (for example, the CZ of New York City, NY also includes Newark, NJ). The same decline in $\beta$ might have different effects in one-state and multi-state CZs. On one hand, if sorting across state borders is more costly than sorting within states, the endogeneity problem might be more pressing in one-state CZs. On the other hand, a decline in $\beta$ in a multi-state $\mathrm{CZ}$ might be driven by a change in revenues and expenditures only in some districts (but not all) and therefore be driven by a much larger absolute change in expenditure in the affected districts. Table AVII shows 2SLS estimates of the main specifications separately for one-state and multi-state CZs. Estimates are fairly comparable in magnitude across the two groups, indicating that the results are not driven by the presence or absence of borders.

\footnotetext{
${ }^{49}$ OLS estimates are shown in Table AVI.
} 


\section{Channels: School Inputs and Intermediate Outcomes}

The results described so far show that equalizing school funding across richer and poorer districts increases intergenerational mobility for children from low-income families. This section investigates the mechanisms behind these effects, focusing on the role of school inputs and on the effects of equalization on intermediate educational outcomes.

\subsection{Inputs: Teacher-Student Ratio}

School finance equalization is often described as a way of "leveling the playing field," i.e., reducing the gap in educational inputs between more and less disadvantaged children. To test this hypothesis I study the effects of equalization on the gap in inputs between low-income and high-income districts. I focus on the teacher-student ratio: Teachers are among the most important factors for student learning (Chetty et al., 2014), and an adequate number of teachers per student is fundamental for the growth in achievement (Krueger and Whitmore, 2001; Bloom and Unterman, 2013). Yet underfunded districts are often forced to cut instructional staff to face budget shortages. ${ }^{50}$

I investigate the effects of a reduction in $\beta$ on the teacher-student ratio, measured at the district-year level, allowing this effect to vary across low-income and high-income districts. I estimate the following equation:

$$
T S_{d t}=\delta_{1} \hat{\beta}_{s(d) t} q_{d t}^{1 q}+\delta_{2} \hat{\beta}_{s(d) t} q_{d t}^{2 q}+\delta_{3} \hat{\beta}_{s(d) t} q_{d t}^{3 q}+\delta_{4} \hat{\beta}_{s(d) t} q_{d t}^{4 q}+\gamma_{d}+\tau_{t}+\varepsilon_{d t}
$$

where $T S_{d t}$ is the teacher-student ratio of district $d$ in year $t$; the variable $q_{d t}^{n q}$ equals 1 for districts in the n-th quartile of the state income distribution in 1990, and the vectors $\gamma_{d}$ and $\tau_{s t}$ control for district and year fixed effects. The parameters $\delta_{1}, \delta_{2}, \delta_{3}$, and $\delta_{4}$ capture the effects of equalization on the teacher-student ratio in districts in the first, second, third and fourth quartile of the income distribution.

Table IX shows OLS and 2SLS estimates of equation (12). OLS results indicate a positive relationship between equalization and the number of teachers per student in low-income districts and a negative (but imprecise) relationship in high-income ones; these effects, however, are indistinguishable from zero (Table IX, column 2). 2SLS estimates, shown in columns 3 and

\footnotetext{
${ }^{50}$ From an analysis of the Center on Budget and Policy Priorities using data from the Bureau of Labor Statistics.
} 
4, yield larger and marginally significant positive effects on low-income districts, but no effect on high-income ones. Controlling for district fixed effects, a one-standard deviation reduction in $\beta$ leads to 0.0076 additional teachers per student in districts in the bottom quartile, or 11 percent more (Table IX, column 4, significant at 5 percent). The same estimate is 0.0017 for districts in the top quartile and it is indistinguishable from zero (Table IX, column 3, p-value equal to 0.68$)$.

Taken together, these estimates indicate that equalizing school spending across richer and poorer districts promotes intergenerational mobility by reducing the gap in educational inputs between low-income and high-income districts. This reduction is achieved through an improvement in the teacher-student ratio in low-income districts, with no significant change in high-income ones.

\subsection{Intermediate Outcome: College Enrollment}

Rothstein (2019) and Chetty et al. (2017) suggest a positive association between college enrollment and intergenerational income mobility. To understand whether higher education is one of the channels through which school finance equalization affects income mobility, I study the effect of equalization on education mobility. To do this, I re-estimate equation (10) using the probability of college enrollment at age 19 (expressed in percentage points and measured separately for each $\mathrm{CZ}$, cohort, and parent percentile within the $\mathrm{CZ}$ ) as the dependent variable.

Controlling for CZ fixed effects, 2SLS estimates indicate that a one-standard deviation reduction in $\beta$ leads to a 7.8 percentage point increase in the probability of college enrollment for children from families at the bottom of the income distribution, although this estimate is imprecise (estimate of $\beta$ equal to -0.0777 , Table $X$, column 1, p-value equal to 0.45 ). Compared with an average probability of 55.6 percent, this implies a 14 percent increase. This effect is reduced by 0.02 percentage points for each additional percentile of parental income (estimate of $\beta \times$ parent centile, Table $\mathrm{X}$, column 1 , significant at 5 percent). These estimates imply that the same reduction in $\beta$ leads to a 7.6 and 7.3 percentage point increase in the probability of college enrollment for children with parents in the 10th and 25th percentile, and a 6.1 percentage point increase for children with parents in the 90th percentile.

Estimates of the heterogeneous effects of a decline in $\beta$ by timing of the reform yields slightly larger effects of equalization in school revenues when experienced during high school, compared to elementary and middle school. A one-standard deviation decline in $\beta$ during 
high school leads to a 37 percentage points increase in the probability of college enrollment for children at the bottom of the parental income distribution; the same reduction leads to a 34 percentage point decline if experienced during elementary or middle school (Table X, column 7, p-values equal to 0.11 and 0.08 , respectively).

These estimates should be interpreted with caution because they are imprecise. They do, however, suggest that access to college could be one of the channels through which school finance equalization improves low-income children's long-run outcomes. The effects of equalization on college enrollment appear slightly larger when equalization is experienced during high school; this can appear in contrast with the estimates in Section 7. Intuitively, however, high school is the moment of a student's career that immediately precedes college; this might explain why equalization in school resources at this particular point in time appears to be important for college access.

\section{Discussion and Conclusion}

This paper studies the effects of equalization in school revenues across public school districts within each state on students' intergenerational income mobility. Using variation in states' funding schemes introduced by school finance reforms and exploiting differences in exposure to equalized schemes across cohorts in different states, I find that equalization increases intergenerational mobility of children from more disadvantaged backgrounds, with insignificant effects on wealthier children. My results also suggest that equalization increases mobility through a reduction in the gap in educational inputs (such as the number of teachers) and in intermediate outcomes (such as college enrollment) between wealthier and poorer districts.

While being a useful source of variation in funding, school finance reforms should be used with caution. Funding formulas link property tax revenues to school spending, and tax revenues could be endogenous to mobility. Changes in tax revenues could happen, for example, if households respond to the change in the tax price introduced by each reform by "voting with their feet" and moving across districts. This sorting affects house prices and the property tax base, which in turn affect school districts' revenues. Importantly, I show that both household incentives to sort across districts and the ultimate effects on equalization are idiosyncratic to each reform; this stresses the importance of keeping this heterogeneity into account in the empirical analysis to obtain unbiased and precise estimates of the effects. 
To account for this source of endogeneity and for the differences in funding formulas across states, I use an instrumental-variable approach that directly exploits the change in the formula type and parameters following each reform. Using hand-collected information on each prereform and post-reform formula type and parameters, combined with district-level data on the variables entering each formula, I simulate each district's post-reform revenues in the absence of sorting. Simulated revenues can then be used as an instrument for actual expenditure. 2SLS estimates are approximately 50 percent larger in magnitude than OLS. This shows that not properly accounting for the endogeneity of post-reform expenditure could lead to biased estimates of the effects of equalization.

At a first glance, these findings might appear in contrast with Rothstein (2019), who uses a correlational analysis to conclude that differences in school quality across the US play a minor role in explaining the observed cross-sectional variation in intergenerational mobility. My results, however, do not necessarily disprove Rothstein's argument. In fact, they confirm that school quality explains a small share (approximately 10 percent) of the total variance in mobility. In spite of this, they also show that equalizing school expenditure has a causal positive effect on the educational and labor market outcomes of disadvantaged children. This in turn implies that this type of policy represents an important engine of mobility for low-income children. These results are in line with Jackson et al. (2015), who show that increased school spending improves long-run outcomes of disadvantaged students. In addition, my analysis highlights the importance of accounting for differences across states in the effects of each reform on revenues and in household responses to each reform, and it proposes the direct use of funding formulas as an instrument to obtain more reliable estimates-an approach that can be used in other studies as well. 


\section{References}

Aaronson, D. (1999). The effect of school finance reform on population heterogeneity. National Tax Journal, 5-29.

Abadie, A., S. Athey, G. W. Imbens, and J. Wooldridge (2017). When should you adjust standard errors for clustering? Technical report, National Bureau of Economic Research.

Acciari, P., A. Polo, and G. Violante (2019). And yet, it moves: Intergenerational economic mobility in italy.

Angrist, J. D. and G. W. Imbens (1995). Two-stage least squares estimation of average causal effects in models with variable treatment intensity. Journal of the American Statistical Association 90(430), 431-442.

Angrist, J. D., G. W. Imbens, and D. B. Rubin (1996). Identification of causal effects using instrumental variables. Journal of the American Statistical Association 91(434), 444-455.

Becker, G. S. and N. Tomes (1979). An equilibrium theory of the distribution of income and intergenerational mobility. Journal of Political Economy, 1153-1189.

Becker, G. S. and N. Tomes (1994). Human capital and the rise and fall of families. In Human Capital: A Theoretical and Empirical Analysis with Special Reference to Education (3rd Edition), pp. 257-298. The University of Chicago Press.

Björklund, A. and M. Jäntti (1997). Intergenerational income mobility in Sweden compared to the United States. American Economic Review 87(5), 1009-1018.

Bloom, H. S. and R. Unterman (2013). Sustained progress: New findings about the effectiveness and operation of small public high schools of choice in New York City.

Bogin, A., W. Doerner, and W. Larson (2016). Local house price dynamics: New indices and stylized facts. Real Estate Economics.

Cameron, A. C. and D. L. Miller (2015). A practitioner's guide to cluster-robust inference. Journal of Human Resources 50(2), 317-372.

Card, D., C. Domnisoru, and L. Taylor (2018). The intergenerational transmission of human capital: Evidence from the golden age of upward mobility. Technical report. 
Card, D. and A. B. Krueger (1992). Does school quality matter? returns to education and the characteristics of public schools in the United States. Journal of Political Economy 100(1), 1-40.

Card, D. and A. A. Payne (2002). School finance reform, the distribution of school spending, and the distribution of student test scores. Journal of Public Economics 83(1), 49-82.

Cascio, E. U., N. Gordon, and S. Reber (2013). Local responses to federal grants: Evidence from the introduction of title i in the south. American Economic Journal: Economic Policy 5(3), 126-59.

Cascio, E. U. and S. Reber (2013). The poverty gap in school spending following the introduction of title i. American Economic Review 103(3), 423-27.

Chakrabarti, R. and J. Roy (2015). Housing markets and residential segregation: Impacts of the Michigan school finance reform on inter-and intra-district sorting. Journal of Public Economics 122, 110-132.

Chetty, R., J. N. Friedman, and J. E. Rockoff (2014). Measuring the impacts of teachers II: Teacher value-added and student outcomes in adulthood. American Economic Review 104(9), 2633-2679.

Chetty, R., J. N. Friedman, E. Saez, N. Turner, and D. Yagan (2017). Mobility report cards: The role of colleges in intergenerational mobility. Technical report, National Bureau of Economic Research.

Chetty, R. and N. Hendren (2018a). The impacts of neighborhoods on intergenerational mobility i: Childhood exposure effects. Quarterly Journal of Economics forthcoming.

Chetty, R. and N. Hendren (2018b). The impacts of neighborhoods on intergenerational mobility ii: County-level estimates. Quarterly Journal of Economics forthcoming.

Chetty, R., N. Hendren, and L. F. Katz (2016). The effects of exposure to better neighborhoods on children: New evidence from the Moving to Opportunity experiment. American Economic Review 106(4), 855-902.

Chetty, R., N. Hendren, P. Kline, and E. Saez (2014). Where is the land of opportunity? the geography of intergenerational mobility in the United States. Quarterly Journal of Economics 129(4), 1553-1623. 
Chetty, R., N. Hendren, P. Kline, E. Saez, and N. Turner (2014). Is the United States still a land of opportunity? recent trends in intergenerational mobility. American Economic Review 104(5), $141-147$.

Coleman, J. S. et al. (1966). Equality of educational opportunity.

Cunha, F. and J. J. Heckman (2010). Investing in our young people. Technical report, National Bureau of Economic Research.

Cunha, F., J. J. Heckman, and S. M. Schennach (2010). Estimating the technology of cognitive and noncognitive skill formation. Econometrica 78(3), 883-931.

Dee, T. S. (2000). The capitalization of education finance reforms. The Journal of Law and Economics 43(1), 185-214.

Downes, T. A., D. N. Figlio, et al. (1997). School finance reforms, tax limits, and student performance: Do reforms level up or dumb down? Institute for Research on Poverty Madison, WI.

Dynarski, S., J. Hyman, and D. W. Schanzenbach (2013). Experimental evidence on the effect of childhood investments on postsecondary attainment and degree completion. Journal of Policy Analysis and Management 32(4), 692-717.

Epple, D. and M. M. Ferreyra (2008). School finance reform: Assessing general equilibrium effects. Journal of Public Economics 92(5-6), 1326-1351.

Figlio, D. N. and M. E. Lucas (2004). What's in a grade? School report cards and the housing market. American Economic Review 94(3), 591-604.

Goldsmith-Pinkham, P., I. Sorkin, and H. Swift (2018). Bartik instruments: What, when, why, and how. Technical report, National Bureau of Economic Research.

Greene, W. H. (2008). Econometric Analysis (6th Edition). Upper Saddle River, N.J. : Prentice Hall.

Gruber, J. and E. Saez (2002). The elasticity of taxable income: evidence and implications. Journal of Public Economics 84(1), 1-32.

Guryan, J. (2001). Does money matter? regression-discontinuity estimates from education finance reform in Massachusetts. Technical report, National Bureau of Economic Research. 
Hanushek, E. A. (1986). The economics of schooling: Production and efficiency in public schools. Journal of Economic Literature, 1141-1177.

Hanushek, E. A. (1997). Assessing the effects of school resources on student performance: An update. Educational Evaluation and Policy Analysis 19(2), 141-164.

Hanushek, E. A. (2003). The failure of input-based schooling policies. The Economic Journal 113(485).

Havnes, T. and M. Mogstad (2015). Is universal child care leveling the playing field? Journal of Public Economics 127, 100-114.

Howell, P. L. and B. B. Miller (1997). Sources of funding for schools. The future of children, $39-50$.

Hoxby, C. M. (1998). How much does school spending depend on family income? the historical origins of the current school finance dilemma. American Economic Review 88(2), 309-314.

Hoxby, C. M. (2001). All school finance equalizations are not created equal. Quarterly Journal of Economics 116(4), 1189-1231.

Hoxby, C. M. and I. Kuziemko (2004). Robin hood and his not-so-merry plan: Capitalization and the self-destruction of texas' school finance equalization plan. Technical report, National Bureau of Economic Research.

Hyman, J. (2017). Does money matter in the long run? Effects of school spending on educational attainment. American Economic Journal: Economic Policy 9(4), 256-80.

Jackson, C. K., R. Johnson, and C. Persico (2014). The effect of school finance reforms on the distribution of spending, academic achievement, and adult outcomes. Technical report, National Bureau of Economic Research.

Jackson, C. K., R. C. Johnson, and C. Persico (2015). The effects of school spending on educational and economic outcomes: Evidence from school finance reforms. Quarterly Journal of Economics 131(1), 157-218.

Krueger, A. B. (1999). Experimental estimates of education production functions. Quarterly Journal of Economics 114(2), 497-532. 
Krueger, A. B. and D. M. Whitmore (2001). The effect of attending a small class in the early grades on college-test taking and middle school test results: Evidence from Project STAR. The Economic Journal 111(468), 1-28.

Lafortune, J., J. Rothstein, and D. W. Schanzenbach (2018). School finance reform and the distribution of student achievement. American Economic Journal: Applied Economics 10(2), $1-26$.

Lee, C.-I. and G. Solon (2009). Trends in intergenerational income mobility. The Review of Economics and Statistics 91(4), 766-772.

Lindseth, A. A. (2004). Educational adequacy lawsuits: The rest of the story. PEPG 04-07. Program on Education Policy and Governance.

Ludwig, J., G. J. Duncan, L. A. Gennetian, L. F. Katz, R. C. Kessler, J. R. Kling, and L. Sanbonmatsu (2013). Long-term neighborhood effects on low-income families: Evidence from Moving to Opportunity. American Economic Review 103(3), 226-31.

Manwaring, R. L. and S. M. Sheffrin (1997). Litigation, school finance reform, and aggregate educational spending. International Tax and Public Finance 4(2), 107-127.

Meghir, C. and M. Palme (2005). Educational reform, ability, and family background. American Economic Review 95(1), 414-424.

Mogstad, M., A. Torgovitsky, and C. R. Walters (2019). Identification of causal effects with multiple instruments: Problems and some solutions. Technical report, National Bureau of Economic Research.

Murray, S. E., W. N. Evans, and R. M. Schwab (1998). Education-finance reform and the distribution of education resources. American Economic Review, 789-812.

Papke, L. E. (2005). The effects of spending on test pass rates: evidence from Michigan. Journal of Public Economics 89(5), 821-839.

Pekkarinen, T., R. Uusitalo, and S. Kerr (2009). School tracking and intergenerational income mobility: Evidence from the finnish comprehensive school reform. Journal of Public Economics 93(7-8), 965-973. 
Picus, L. O. and L. Hertert (1993). Three strikes and you're out: Texas school finance after Edgewood III. Journal of Education Finance, 366-389.

Rothstein, J. (2019). Inequality of educational opportunity? schools as mediators of the intergenerational transmission of income. Journal of Labor Economics 37(S1), S85-S123.

Roy, J. (2011). Impact of school finance reform on resource equalization and academic performance: Evidence from Michigan. Education 6(2), 137-167.

Silva, F. and J. Sonstelie (1995). Did serrano cause a decline in school spending? National Tax Journal, 199-215.

Solon, G. (1992). Intergenerational income mobility in the United States. American Economic Review, 393-408.

Solon, G. (1999). Intergenerational mobility in the labor market. Handbook of Labor Economics 3, 1761-1800.

Solon, G. (2002). Cross-country differences in intergenerational earnings mobility. Journal of Economic Perspectives 16(3), 59-66.

Stevens, N. (1989). Texas school finance system: New legislation. Journal of Education Finance, 269-277.

Stock, J. H. and M. Yogo (2002). Testing for weak instruments in linear iv regression.

Tiebout, C. M. (1956). A pure theory of local expenditures. Journal of Political Economy, 416-424.

Verstegen, D. A. and T. S. Jordan (2009). A fifty-state survey of school finance policies and programs: An overview. Journal of Education Finance, 213-230.

Wolff, E. N. and A. Zacharias (2009). Household wealth and the measurement of economic well-being in the United States. The Journal of Economic Inequality 7(2), 83-115. 
Figure I: Event Study of Equalization Measure $\beta$ Around A School Finance Reform

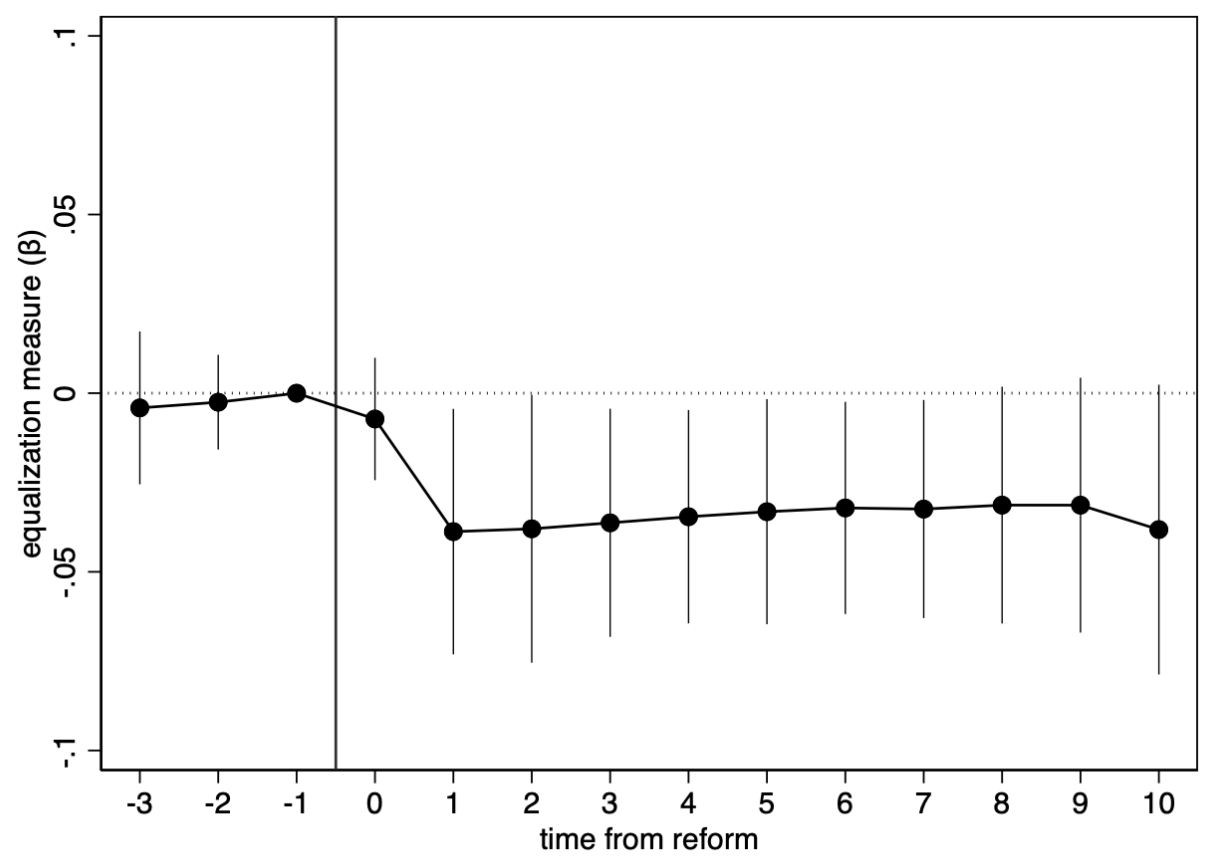

Note: Point estimates and 90 percent confidence intervals for the coefficients $\delta_{k}$ in regression $\beta_{s t}=\sum_{k} \delta_{k} R_{s} 1\left(t-\right.$ ryear $\left._{s}=k\right)+\varepsilon_{s t}$, where $\beta_{s t}$ is the slope coefficient in equation (6), estimated separately for each state $s$ and year $t$ from 1986 to 2004, $R_{s}$ equals 1 if state $s$ had a school finance reform in the years 1980-2004, and ryear $_{s}$ is the year of the first reform in this time period. The coefficient $\delta_{-1}$ is normalized to equal zero. Standard errors are clustered at the state level. The sample is restricted to California, Colorado, Florida, Georgia, Illinois, Kentucky, Louisiana, Massachusetts, Michigan, Minnesota, Montana, Nebraska, New Jersey, New York, North Dakota, Ohio, Pennsylvania, Utah, Texas, and Wisconsin. 
Figure II: Equalization Measure $\beta$ Around A School Finance Reform - Selected States

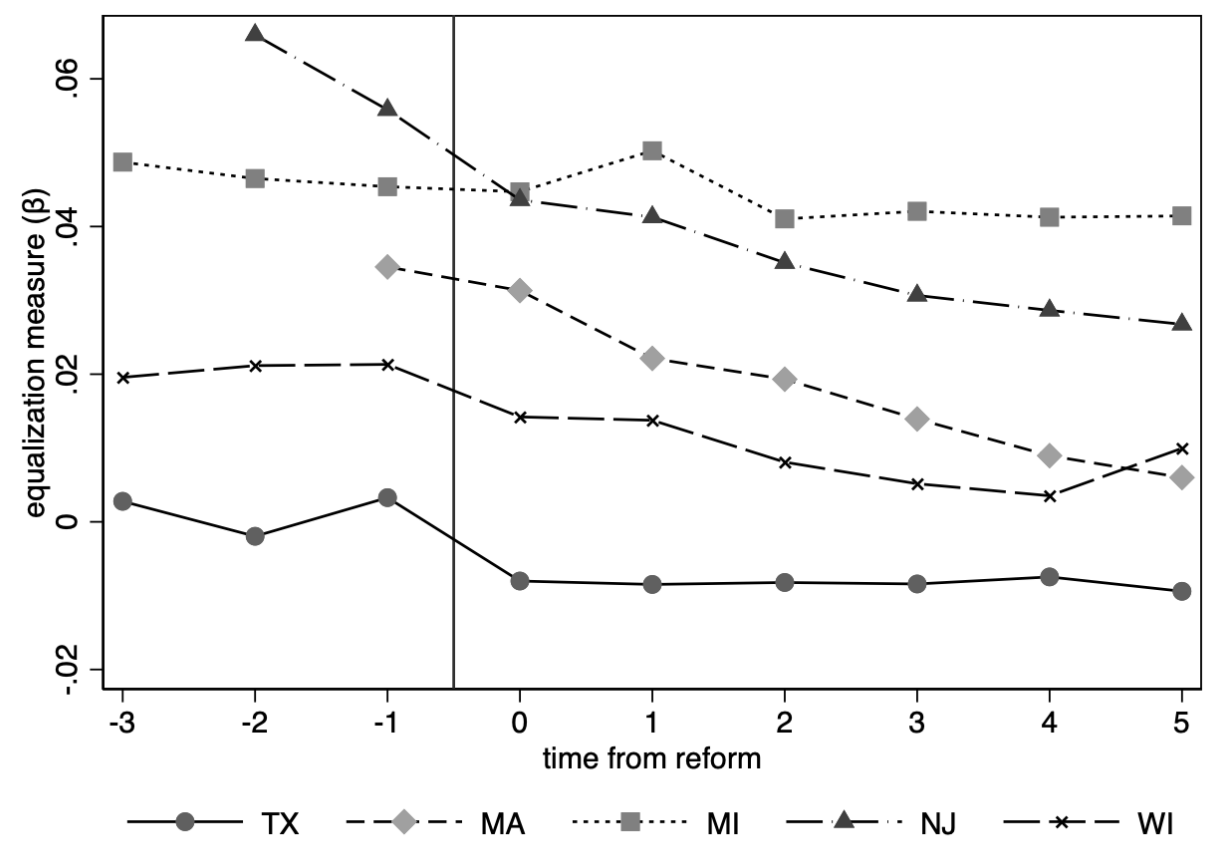

Note: The figure shows estimates of the coefficient $\beta_{s t}$ (defined in equation (6)) for a sample of states in the years surrounding each school finance reform. 
Figure III: Event Studies of Migration Rates (Top Panel) and Incomes of Migrants vs Incumbents (Bottom Panel) Around A School Finance Reform
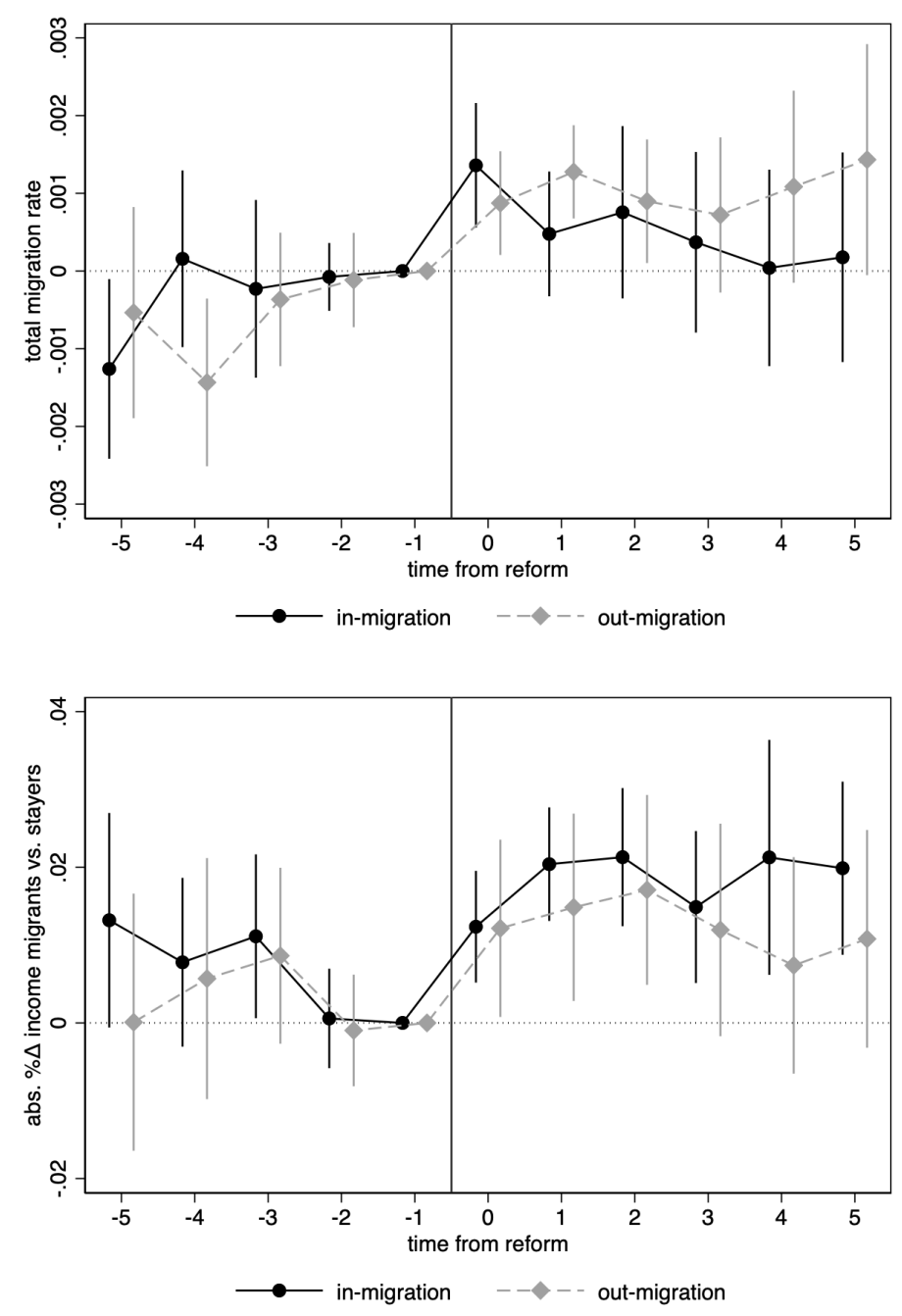

Note: Changes in total migration rates and incomes of migrants in a 10-year window around each school finance reform. Each point and spike represent the estimate and the 90 percent confidence interval of the coefficients $\delta_{n}$ in the regression $y_{k t}=\sum_{n=-5}^{5} \delta_{n} R_{s(k)} 1\left(t-\right.$ ryear $_{k}=$ $n)+\gamma_{k}+\tau_{t}+\varepsilon_{k t}$, where $R_{s(k)}$ equals 1 if state $s$ of county $k$ experienced a school finance reform in the years 1980-2004, ryear $_{s(k)}$ is the year of the earliest reform, $\gamma_{k}$ are county fixed effects, and $\tau_{t}$ are year fixed effects. In the top panel, $y_{k t}$ is the total in-migration or outmigration rate in county $k$ and year $t$ (the ratio between the sum of in-migrants or out-migrants and the total population in each county). In the bottom panel, $y_{k t}$ is the absolute percentage difference between incomes of in-migrants or out-migrants and incomes of stayers in county $k$ and year $t$, divided by 100 . Standard errors are clustered at the county level. County-year level observations are weighted by population. Data on migration are from the Statistics of Income of the Internal Revenue Service and cover years from 1991 to 2004. 
Figure IV: Variation in House Prices Around a School Finance Reform - Selected States

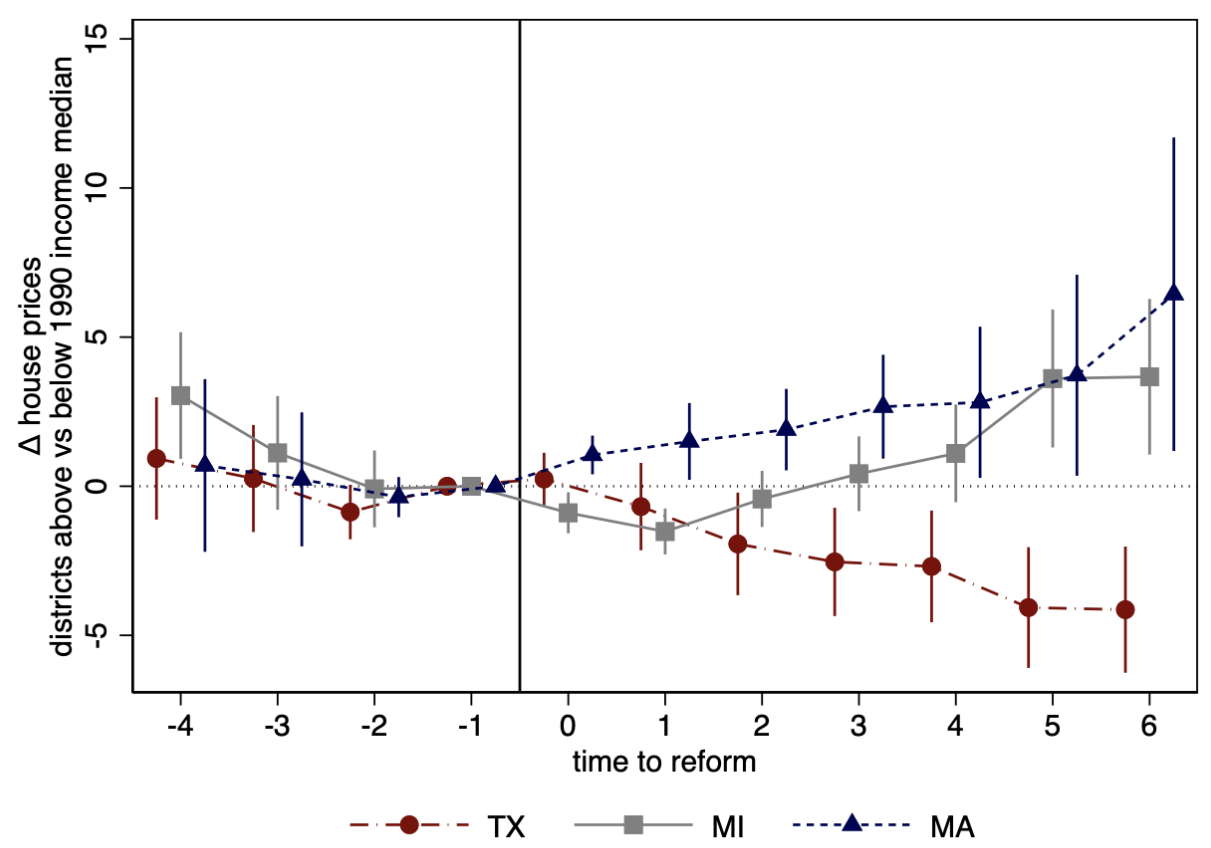

Note: Changes in the difference in house prices between households with incomes above and below the median in 1990, in a 10-year window around each reform and relative to the year before the reform. Each point and spike represent the estimate and the 90 percent confidence interval of the coefficients $\delta_{n}$ in the regression $H P_{d t}=\sum_{n=-4}^{6} \delta_{n} 1$ Income $_{d, 1990}>$ Median $\left._{s}\right) R_{s(d)} 1\left(t-\right.$ ryear $\left._{s(d)}=n\right)+\theta_{d}+\tau_{t}+\varepsilon_{d t}$, where $H P_{d t}$ is the house price index of district $d$ in year $t$, Income I, $1990_{\text {is average household income of district } d \text { in 1990, Median }}$ is median household income across districts in state $s$ in 1990, $R_{s(d)}$ equals 1 if state $s$ where the district is located experienced a school finance reform in the years 1980-2004, ryear $_{s(d)}$ is the year of the earliest reform, and $\theta_{d}$ and $\tau_{t}$ are district and year fixed effects. The coefficient $\delta_{-1}$ is normalized to zero. The parameters are estimated separately for each state. Standard errors are clustered at the district level. Observations are weighted by population. Annual House Price Indexes data are taken from the FHFA, aggregated at the district level using population weights, and cover years from 1986 to 2004. 
Figure V: Simulated and Actual Revenues, Districts In The Top And Bottom Quartiles of Expenditure - Selected States
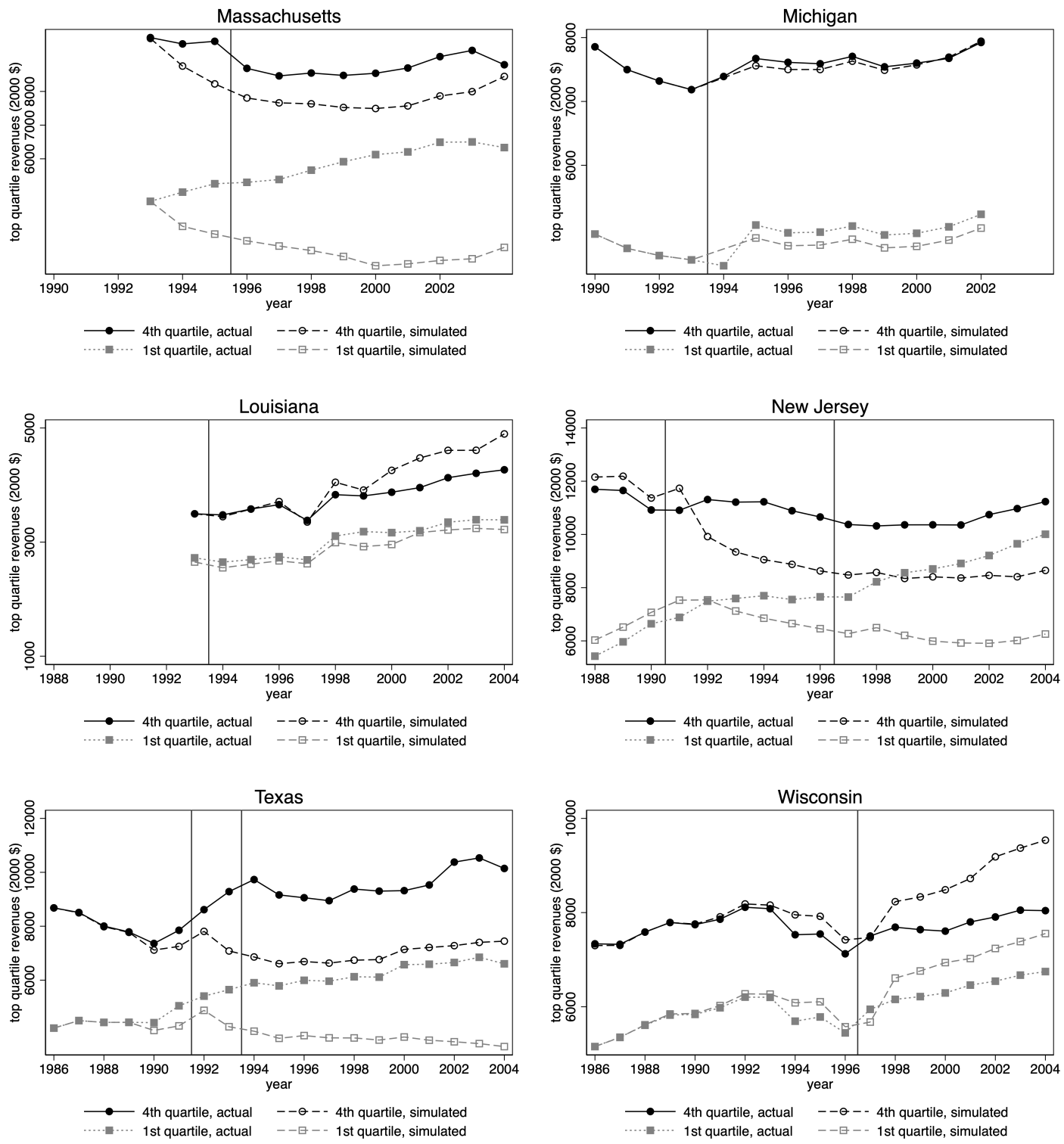

Note: Trends in average simulated and actual per pupil revenues, for districts in the top and bottom quartiles of the state's distribution of per pupil expenditure at the beginning of each sample. Vertical lines denote reform years. Simulated expenditures are calculated using the funding formula in place in every state and year and pre-reform district variables, using the procedure described in the text. 
Figure VI: Changes in Intergenerational Income Mobility by Exposure to a School Finance Reform, in States with Effective vs. Ineffective Reforms

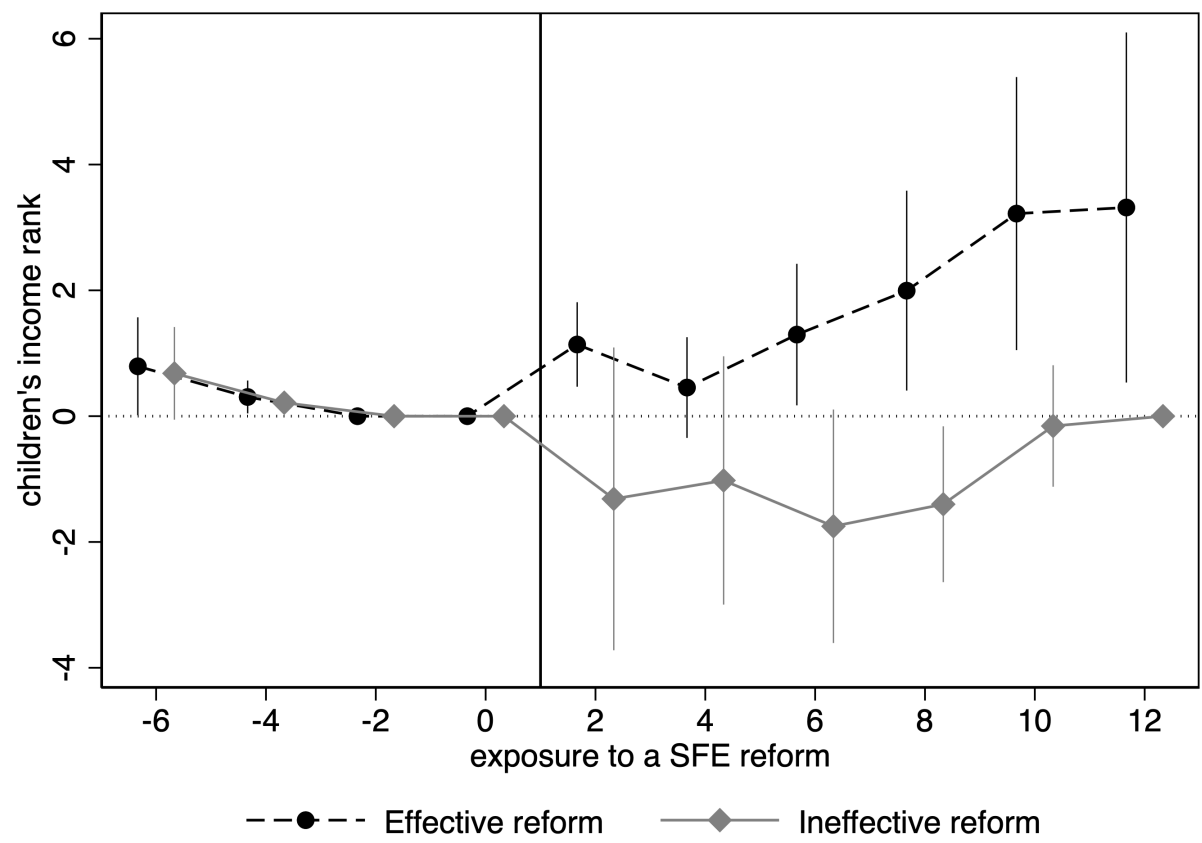

Note: The figure shows OLS points estimates and 90 percent confidence intervals of the coefficients $\delta_{n}$ in the equation $m_{c b}=\sum_{n=-6}^{12} \delta_{n} E_{n(s b)}+\theta_{c}+\tau_{b}+\varepsilon_{c v}$, where $m_{c b}$ is the mean rank of children in $\mathrm{CZ} c$, cohort $b$, and with parents' income on the 25th percentile in the national income distribution, $E_{n}$ equals one if cohort $b$ in state $s$ was exposed to a post-school finance reform regime for $n$ years (and $E_{n}=b+17-$ ryear $_{s}$, where ryear $r_{s}$ is the year of the first school finance reform in state $s$ between 1980 and 2004), and the vectors $\theta_{c}$ and $\tau_{b}$ contain CZ and cohort fixed effects. Estimates are obtained and shown separately for states with effective reforms (i.e. those which resulted in a negative post-reform $\beta$ or a decline in $\beta$ of at least 50 percent, including Colorado, Kentucky, Montana, Nebraska, Texas, and Wisconsin, solid line) and ineffective reforms (including Louisiana, Massachusetts, Michigan, Minnesota, and New Jersey, dashed line), using states with no reform (including California, Florida, Georgia, Illinois, New York, North Dakota, Ohio, Pennsylvania, and Utah) as a control group. Observations are at the $\mathrm{CZ} \times$ birth cohort level, and they are weighted by the number of children in each $\mathrm{CZ}$ and cohort. The coefficient $\delta_{0}$ is normalized to equal zero for both groups. Standard errors are clustered at the state and cohort level. 
Figure VII: Effect of an Increase in $\beta$, by Parents' Income Percentile

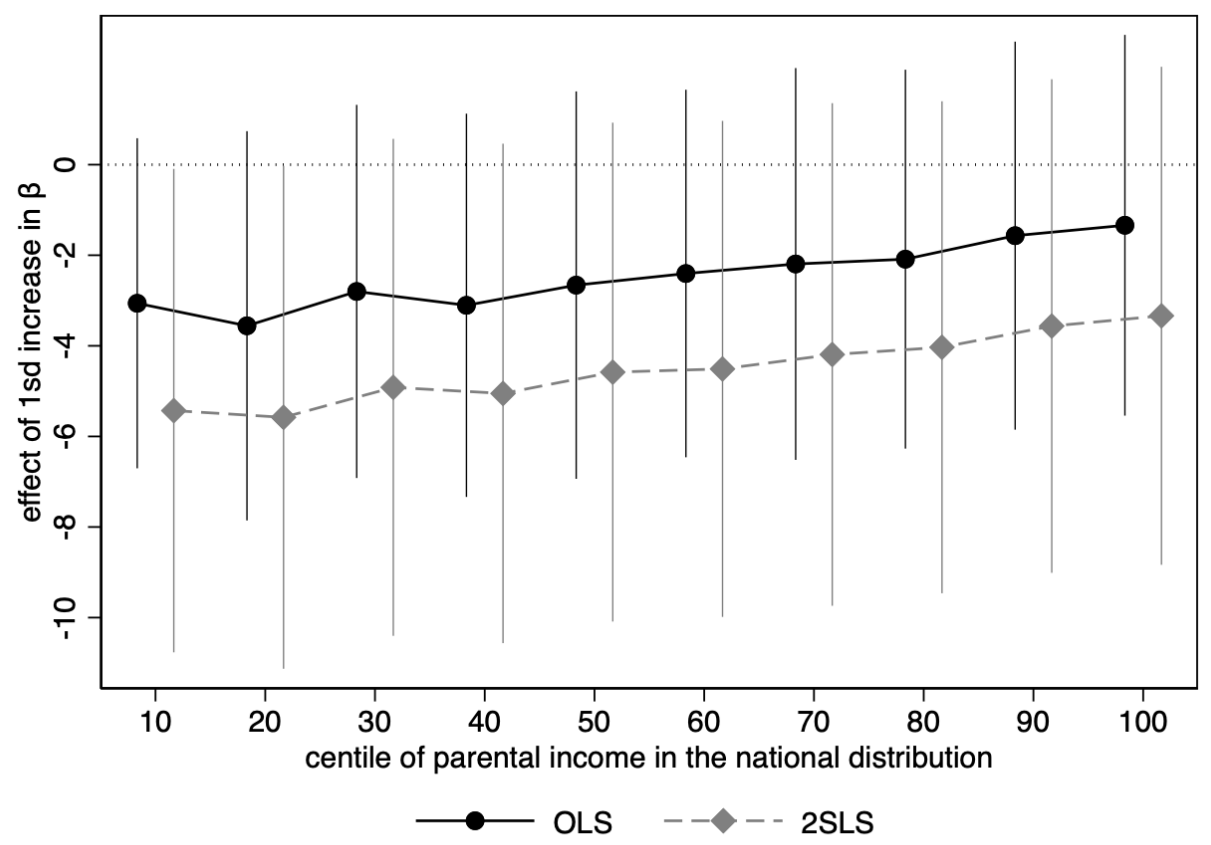

Note: OLS (solid line) and 2SLS (dashed line) estimates and 90-percent confidence intervals for the coefficients $\delta_{d}$ in the regression $M_{c x b}=\sum_{d=1}^{10} \delta_{d} D_{d(c x)} \hat{\beta}_{s(c) b}+\kappa_{c}+\theta_{n(x c)}+\sigma_{b}+\omega_{c x b}$, where $M_{c x b}$ is the average national income percentile of children with parents on the $x$ percentile of the $\mathrm{CZ}$ income distribution, born in cohort $b$ in $\mathrm{CZ} c, \hat{\beta}_{s(c) b}$ is the estimated, cohort-specific measure of school finance equalization, $D_{d(c x)}$ equals 1 if the income of the parents of children in cohort $c$ and percentile $x$ falls in decile $d$ of the national distribution, $\theta_{n(x c)}$ are fixed effects for the parent percentile on the national income distribution, $\kappa_{c}$ are $\mathrm{CZ}$ fixed effects, and $\sigma_{b}$ are cohort fixed effects. Standard errors are clustered at the state and birth level. The sample is restricted to California, Colorado, Florida, Georgia, Illinois, Kentucky, Louisiana, Massachusetts, Michigan, Minnesota, Montana, Nebraska, New Jersey, New York, North Dakota, Ohio, Pennsylvania, Utah, Texas, and Wisconsin. 
Table I: Summary Statistics: School District Revenues, Intergenerational Mobility, and Measures of Equalization $(\beta)$

Panel A: Per Pupil Revenues and Income

\begin{tabular}{lcccccc}
\hline \hline & mean & sd & median & min & max & N \\
\hline Median income & & & & & & \\
1980 & 36417 & 11041 & 33961 & 18286 & 67924 & 7578 \\
1990 & 46552 & 17916 & 41249 & 18149 & 115499 & 7621 \\
2000 & 44018 & 15891 & 37500 & 17500 & 87500 & 7936 \\
2010 & 42974 & 16444 & 46250 & 14800 & 92500 & 7942 \\
\hline exp, richest vs poorest district within state $(\$)$ & & & & & & \\
1986 & 3031 & 5964 & -1065 & -1262 & 14162 & 2788 \\
1990 & 4012 & 4539 & 2320 & -4024 & 12965 & 4895 \\
2000 & 2135 & 6242 & 885 & -13014 & 15415 & 7146 \\
2004 & 1185 & 7264 & -330 & -8083 & 18120 & 6653 \\
\hline exp, richest vs poorest district within CZ $(\$)$ & & & & & & \\
1986 & 1291 & 4731 & 377 & -13816 & 13890 & 2788 \\
1990 & 1223 & 3750 & 451 & -11045 & 14518 & 4895 \\
2000 & 104 & 5046 & -153 & -16378 & 17917 & 7146 \\
2004 & 297 & 5744 & -256 & -16299 & 18332 & 6653
\end{tabular}

Panel B: Intergenerational Income Mobility Measures

Expected Income Percentile of Children by Percentile of the Parents

\begin{tabular}{lcccc}
\hline \hline & 10 th & 25th & 75 th & 90 th \\
\hline $1980-82$ & 0.394 & 0.435 & 0.569 & 0.609 \\
& $(0.040)$ & $(0.033)$ & $(0.024)$ & $(0.028)$ \\
$1983-86$ & 0.398 & 0.437 & 0.567 & 0.607 \\
& $(0.034)$ & $(0.030)$ & $(0.031)$ & $(0.036)$ \\
$\mathrm{N}(\mathrm{CZs})$ & 589 & 589 & 589 & 589 \\
\hline \hline
\end{tabular}

\begin{tabular}{lccccc}
\hline \hline \multicolumn{5}{c}{ Panel C: Measures of School Finance Equalization $(\beta)$} \\
\hline$\beta$ & All & No reform & Pre-Reform & Post-Reform & Difference \\
\hline$\beta_{s}$ & 0.011 & 0.028 & 0.044 & -0.009 & $-0.053^{* * *}$ \\
& $(0.068)$ & $(0.091)$ & $(0.038)$ & $(0.048)$ & $(0.008)$ \\
$\mathrm{N}(\mathrm{CZs})$ & 0.016 & 0.028 & 0.044 & -0.000 & $-0.045^{* * *}$ \\
\hline \hline
\end{tabular}

Note: Panel A: Summary statistics of income and per-pupil revenues (measured in 2000 dollars), and difference in per-pupil revenues between the highest-income district and the lowest-income district within each state and CZ. Panel B: Means and standard deviations of CZ-cohort level intergenerational mobility measures for cohorts 1980 to 1986, published as part of the Opportunity Insights Project (https://opportunityinsights.org/). Panel C: means and standard deviations of the slope coefficient in equation (6), estimated separately for each state and year using actual revenues $(\beta)$ and simulated revenues $\left(\beta^{\text {sim }}\right)$. In Panels A and C, the sample is restricted to school districts and CZs in 20 states with available data to construct the simulated instruments. 
Table II: School Finance Equalization and Intergenerational Mobility. OLS, Dependent Variable is Children's Income Percentile

\begin{tabular}{|c|c|c|c|c|}
\hline & (1) & (2) & (3) & (4) \\
\hline$\beta$ & $\begin{array}{l}-3.8397 \\
(2.1546)\end{array}$ & $\begin{array}{l}-3.7174 \\
(2.1259)\end{array}$ & $\begin{array}{l}-3.7667 \\
(2.2392)\end{array}$ & $\begin{array}{l}-3.6370 \\
(2.2195)\end{array}$ \\
\hline$\beta \times$ parent centile & $\begin{array}{c}0.0246^{* * *} \\
(0.0044)\end{array}$ & $\begin{array}{c}0.0239^{* * *} \\
(0.0044)\end{array}$ & $\begin{array}{c}0.0246^{* * *} \\
(0.0044)\end{array}$ & $\begin{array}{c}0.0239^{* * *} \\
(0.0044)\end{array}$ \\
\hline$e_{s b}(\$ 1,000)$ & & & $\begin{array}{c}0.2472 \\
(0.8907)\end{array}$ & $\begin{array}{c}0.2729 \\
(0.8886)\end{array}$ \\
\hline Parent centile FE & Yes & Yes & Yes & Yes \\
\hline Cohort FE & Yes & Yes & Yes & Yes \\
\hline CZ FE & Yes & No & Yes & No \\
\hline State FE & No & Yes & No & Yes \\
\hline $\mathrm{N}(\mathrm{CZ} \times$ parent cent. $\times$ cohort $)$ & 13578 & 13578 & 13578 & 13578 \\
\hline \multicolumn{5}{|c|}{ Effect of a 1sd $\downarrow \beta$ by parents' percentile: } \\
\hline 10th & 3.593 & 3.478 & 3.520 & 3.398 \\
\hline 10th [p-value] & [0.146] & [0.153] & [0.166] & [0.177] \\
\hline 25 th & 3.224 & 3.119 & 3.151 & 3.038 \\
\hline 25th [p-value] & [0.184] & [0.194] & [0.207] & [0.220] \\
\hline 90th & 1.622 & 1.562 & 1.549 & 1.482 \\
\hline 90th [p-value] & [0.480] & [0.499] & [0.512] & [0.534] \\
\hline
\end{tabular}

Note: The table shows OLS estimates of the parameters $\delta_{0}$ and $\delta$ in equation (10). The dependent variable is children's income percentile in the national distribution for each parental income percentile in the distribution of each $\mathrm{CZ}$, for cohorts 1980 to 1986 . The variable $\beta$ is the OLS estimate of the slope coefficient in equation (6), computed separately for each state and cohort, and standardized across all states and cohorts. The variable parent centile is the percentile of parents in the national income distribution. The variable $e_{s}$ is average per-pupil expenditure for each state and cohort. All specifications include parent percentile and cohort fixed effects; columns 1 and 3 include $\mathrm{CZ}$ fixed effects, and columns 2 and 4 include state fixed effects. Standard errors in parentheses are clustered at the state and birth cohort level. The sample is restricted to California, Colorado, Florida, Georgia, Illinois, Kentucky, Louisiana, Massachusetts, Michigan, Minnesota, Montana, Nebraska, New Jersey, New York, North Dakota, Ohio, Pennsylvania, Utah, Texas, and Wisconsin. ${ }^{* * *} \mathrm{p}<0.01,{ }^{* *} \mathrm{p}<0.05,{ }^{*} \mathrm{p}<0.1$. 
Table III: School Finance Equalization and Intergenerational Mobility. 2SLS, First Stage

\begin{tabular}{|c|c|c|c|c|}
\hline & $\beta$ & $\beta \times$ parent centile & $\beta$ & $\beta \times$ parent centile \\
\hline & (1) & (2) & (3) & (4) \\
\hline$\beta$ simulated & $\begin{array}{c}0.7526^{* * *} \\
(0.1204)\end{array}$ & $\begin{array}{c}-12.6055^{*} \\
(6.2276)\end{array}$ & $\begin{array}{c}0.7525^{* * *} \\
(0.1203)\end{array}$ & $\begin{array}{c}-12.5859^{*} \\
(6.2186)\end{array}$ \\
\hline$\beta$ simulated $\times$ parent centile & $\begin{array}{c}0.0000 \\
(0.0000)\end{array}$ & $\begin{array}{c}0.9908^{* * *} \\
(0.0163)\end{array}$ & $\begin{array}{c}0.0000 \\
(0.0000)\end{array}$ & $\begin{array}{c}0.9907^{* * *} \\
(0.0166)\end{array}$ \\
\hline Parent centile FE & Yes & Yes & Yes & Yes \\
\hline Cohort FE & Yes & Yes & Yes & Yes \\
\hline CZ FE & Yes & Yes & No & No \\
\hline State FE & No & No & Yes & Yes \\
\hline Kleibergen-Paap Wald F-stat & 19.56 & & 19.58 & \\
\hline $\mathrm{N}(\mathrm{CZ} \times$ parent cent. $\times$ cohort $)$ & 13578 & 13578 & 13578 & 13578 \\
\hline
\end{tabular}

Note: The table shows the first stage of the 2SLS estimation of the parameters $\delta_{0}$ and $\delta$ in equation (10). The variable $\beta$ is the OLS estimate of the slope coefficient in equation (6), computed separately for each state and cohort, and standardized across all states and cohorts. The variable parent centile is the percentile of parents in the national income distribution. The variable $\beta$ simulated is estimated as $\beta$ using simulated revenues instead of actual revenues. In this first stage, the variables $\beta$ simulated and $\beta$ simulated $\times$ parent centile are used as instruments for $\beta$ and $\beta \times$ parent centile. All specifications include parent percentile and cohort fixed effects; columns 1 and 2 include $\mathrm{CZ}$ fixed effects, and columns 3 and 4 include state fixed effects. Standard errors in parentheses are clustered at the state and birth cohort level. The sample is restricted to California, Colorado, Florida, Georgia, Illinois, Kentucky, Louisiana, Massachusetts, Michigan, Minnesota, Montana, Nebraska, New Jersey, New York, North Dakota, Ohio, Pennsylvania, Utah, Texas, and Wiscon$\sin .{ }^{* * *} \mathrm{p}<0.01,{ }^{* *} \mathrm{p}<0.05,{ }^{*} \mathrm{p}<0.1$. 
Table IV: School Finance Equalization and Intergenerational Mobility. 2SLS, Dependent Variable is Children's Income Percentile

\begin{tabular}{|c|c|c|c|c|c|c|}
\hline & $(1)$ & $(2)$ & (3) & $(4)$ & (5) & (6) \\
\hline$\beta$ & $\begin{array}{l}-5.8120^{*} \\
(2.8364)\end{array}$ & $\begin{array}{l}-5.6920^{*} \\
(2.8014)\end{array}$ & $\begin{array}{l}-5.6430^{*} \\
(2.6623)\end{array}$ & $\begin{array}{l}-5.4974^{*} \\
(2.6271)\end{array}$ & & \\
\hline$\beta \times$ parent centile & $\begin{array}{c}0.0253^{* * *} \\
(0.0044)\end{array}$ & $\begin{array}{c}0.0244^{* * *} \\
(0.0044)\end{array}$ & $\begin{array}{c}0.0253^{* * *} \\
(0.0044)\end{array}$ & $\begin{array}{c}0.0244^{* * *} \\
(0.0044)\end{array}$ & & \\
\hline$e_{s b}(\$ 1,000)$ & & & $\begin{array}{c}0.1731 \\
(0.9230)\end{array}$ & $\begin{array}{c}0.1993 \\
(0.9195)\end{array}$ & & \\
\hline$\beta$ simulated & & & & & $\begin{array}{c}-4.6927^{*} \\
(1.9486)\end{array}$ & $\begin{array}{l}-4.5900^{*} \\
(1.9184)\end{array}$ \\
\hline$\beta$ simulated $\times$ parent centile & & & & & $\begin{array}{c}0.0250^{* * *} \\
(0.0044)\end{array}$ & $\begin{array}{c}0.0241^{* * *} \\
(0.0043)\end{array}$ \\
\hline Parent centile FE & Yes & Yes & Yes & Yes & Yes & Yes \\
\hline Cohort FE & Yes & Yes & Yes & Yes & Yes & Yes \\
\hline CZ FE & Yes & No & Yes & No & Yes & No \\
\hline State FE & No & Yes & No & Yes & No & Yes \\
\hline $\mathrm{N}(\mathrm{CZ} \times$ parent cent. $\times$ cohort $)$ & 13578 & 13578 & 13578 & 13578 & 13578 & 13578 \\
\hline \multicolumn{7}{|c|}{ Effect of a 1sd $\downarrow \beta$ by parents' percentile: } \\
\hline 10th & 5.559 & 5.448 & 5.390 & 5.253 & 4.443 & 4.349 \\
\hline 10th [p-value] & [0.097] & [0.100] & [0.088] & [0.092] & {$[0.063]$} & {$[0.064]$} \\
\hline 25 th & 5.181 & 5.082 & 5.012 & 4.888 & 4.068 & 3.987 \\
\hline 25th [p-value] & [0.117] & [0.120] & [0.106] & [0.111] & [0.082] & {$[0.084]$} \\
\hline 90th & 3.539 & 3.497 & 3.370 & 3.302 & 2.443 & 2.418 \\
\hline 90th [p-value] & [0.256] & [0.262] & [0.242] & [0.252] & [0.263] & [0.270] \\
\hline
\end{tabular}

Note: The table shows 2SLS second-stage estimates of the parameters $\delta_{0}$ and $\delta$ in equation (10). The dependent variable is children's income percentile in the national distribution for each parental income percentile in the distribution of each CZ, for cohorts 1980 to 1986. The variable $\beta$ is the OLS estimate of the slope coefficient in equation (6), computed separately for each state and cohort, and standardized across all states and cohorts. The variable parent centile is the percentile of parents in the national income distribution. The variable $e_{s}$ is average per-pupil expenditure for each state and cohort. The variables $\beta$ and $\beta \times$ parent centile are instrumented using $\beta$ simulated and $\beta$ simulated $\times$ parent centile; the variable $\beta$ simulated is estimated as $\beta$ using simulated revenues instead of actual revenues. All specifications include parent percentile and cohort fixed effects; columns 1, 3, and 5 include CZ fixed effects, and columns 2, 4, and 6 include state fixed effects. Standard errors in parentheses are clustered at the state and birth cohort level. The sample is restricted to California, Colorado, Florida, Georgia, Illinois, Kentucky, Louisiana, Massachusetts, Michigan, Minnesota, Montana, Nebraska, New Jersey, New York, North Dakota, Ohio, Pennsylvania, Utah, Texas, and Wisconsin. ${ }^{* *} \mathrm{p}<0.01,{ }^{* *} \mathrm{p}<0.05,{ }^{*} \mathrm{p}<0.1$. 
Table V: School Finance Equalization and Intergenerational Mobility. OLS and 2SLS, Dependent Variable is Children's log(Income)

\begin{tabular}{|c|c|c|c|c|}
\hline & \multicolumn{2}{|c|}{ OLS } & \multicolumn{2}{|c|}{ 2SLS, Second stage } \\
\hline & $(1)$ & $(2)$ & (3) & $(4)$ \\
\hline$\beta$ & $\begin{array}{l}-0.1035 \\
(0.0566)\end{array}$ & $\begin{array}{l}-0.1004 \\
(0.0557)\end{array}$ & $\begin{array}{l}-0.1574^{*} \\
(0.0761)\end{array}$ & $\begin{array}{l}-0.1541^{*} \\
(0.0752)\end{array}$ \\
\hline$\beta \times$ parent centile & $\begin{array}{c}0.0007^{* * *} \\
(0.0001)\end{array}$ & $\begin{array}{c}0.0007^{* * *} \\
(0.0001)\end{array}$ & $\begin{array}{c}0.0007^{* * *} \\
(0.0001)\end{array}$ & $\begin{array}{c}0.0007^{* * *} \\
(0.0001)\end{array}$ \\
\hline Parent centile FE & Yes & Yes & Yes & Yes \\
\hline Cohort FE & Yes & Yes & Yes & Yes \\
\hline CZ FE & Yes & No & Yes & No \\
\hline State FE & No & Yes & No & Yes \\
\hline $\mathrm{N}(\mathrm{CZ} \times$ parent cent. $\times$ cohort $)$ & 13578 & 13578 & 13578 & 13578 \\
\hline \multicolumn{5}{|c|}{ Effect of a 1sd $\downarrow \beta$ by parents' percentile: } \\
\hline 10th & 0.101 & 0.098 & 0.162 & 0.158 \\
\hline 10th [p-value] & [0.138] & {$[0.144]$} & [0.095] & [0.098] \\
\hline 25th & 0.089 & 0.086 & 0.149 & 0.146 \\
\hline 25th [p-value] & [0.178] & [0.187] & [0.115] & [0.119] \\
\hline 90th & 0.039 & 0.038 & 0.095 & 0.094 \\
\hline 90th [p-value] & [0.515] & [0.532] & [0.269] & [0.275] \\
\hline
\end{tabular}

Note: The table shows OLS (columns 1 and 2) and 2SLS second-stage estimates (columns 3 and 4 ) of the parameters $\delta_{0}$ and $\delta$ in equation (10). The dependent variable is the natural logarithm of children's income for each parental income percentile in the distribution of each CZ, for cohorts 1980 to 1986. The variable $\beta$ is the OLS estimate of the slope coefficient in equation (6), computed separately for each state and cohort, and standardized across all states and cohorts. The variable parent centile is the percentile of parents in the national income distribution. In columns 3 and 4 , the variables $\beta$ and $\beta \times$ parent centile are instrumented using $\beta$ simulated and $\beta$ simulated $\times$ parent centile; the variable $\beta$ simulated is estimated as $\beta$ using simulated revenues instead of actual revenues. All specifications include parent percentile and cohort fixed effects; columns 1 and 3 include CZ fixed effects, and columns 2 and 4 include state fixed effects. Standard errors in parentheses are clustered at the state and birth cohort level. The sample is restricted to California, Colorado, Florida, Georgia, Illinois, Kentucky, Louisiana, Massachusetts, Michigan, Minnesota, Montana, Nebraska, New Jersey, New York, North Dakota, Ohio, Pennsylvania, Utah, Texas, and Wisconsin. ${ }^{* * *} \mathrm{p}<0.01,{ }^{* *} \mathrm{p}<0.05,{ }^{*} \mathrm{p}<0.1$. 
Table VI: Heterogeneous Effects of School Finance Equalization Across School Grades. OLS and 2SLS, Dependent Variable is Children's Income Percentile

\begin{tabular}{|c|c|c|c|c|}
\hline & \multicolumn{2}{|c|}{ OLS } & \multicolumn{2}{|c|}{ 2SLS } \\
\hline & $(1)$ & $(2)$ & $(3)$ & $(4)$ \\
\hline$\beta \times$ reform in elementary school & $\begin{array}{l}-3.5210 \\
(2.6070)\end{array}$ & $\begin{array}{l}-3.1433 \\
(2.5024)\end{array}$ & $\begin{array}{l}-8.4582^{*} \\
(4.0107)\end{array}$ & $\begin{array}{c}-8.0583^{*} \\
(3.9468)\end{array}$ \\
\hline$\beta \times$ parent centile $\times$ reform in elementary school & $\begin{array}{c}0.0704^{* *} \\
(0.0269)\end{array}$ & $\begin{array}{c}0.0676^{* *} \\
(0.0235)\end{array}$ & $\begin{array}{c}0.0859^{* * *} \\
(0.0193)\end{array}$ & $\begin{array}{c}0.0810^{* * *} \\
(0.0169)\end{array}$ \\
\hline$\beta \times$ reform in middle school & $\begin{array}{c}-1.4628 \\
(1.7470)\end{array}$ & $\begin{array}{c}-1.3803 \\
(1.7809)\end{array}$ & $\begin{array}{l}-4.4117 \\
(2.9891)\end{array}$ & $\begin{array}{c}-4.3311 \\
(2.9831)\end{array}$ \\
\hline$\beta \times$ parent centile $\times$ reform in middle school & $\begin{array}{c}0.0237^{* *} \\
(0.0087)\end{array}$ & $\begin{array}{l}0.0240^{* *} \\
(0.0098)\end{array}$ & $\begin{array}{l}0.0241^{*} \\
(0.0105)\end{array}$ & $\begin{array}{c}0.0241^{*} \\
(0.0113)\end{array}$ \\
\hline$\beta \times$ reform in high school & $\begin{array}{l}-1.5429 \\
(1.7644)\end{array}$ & $\begin{array}{c}-1.4843 \\
(1.7677)\end{array}$ & $\begin{array}{c}-4.2956 \\
(3.3262)\end{array}$ & $\begin{array}{l}-4.2679 \\
(3.2903)\end{array}$ \\
\hline$\beta \times$ parent centile $\times$ reform in high school & $\begin{array}{c}0.0201^{* *} \\
(0.0074)\end{array}$ & $\begin{array}{c}0.0198^{* *} \\
(0.0076)\end{array}$ & $\begin{array}{l}0.0195^{* *} \\
(0.0074)\end{array}$ & $\begin{array}{c}0.0193^{* *} \\
(0.0076)\end{array}$ \\
\hline Parent centile FE & Yes & Yes & Yes & Yes \\
\hline Cohort FE & Yes & Yes & Yes & Yes \\
\hline CZ FE & Yes & No & Yes & No \\
\hline State FE & No & Yes & No & Yes \\
\hline Reform in elem, middle, high & Yes & Yes & Yes & Yes \\
\hline $\mathrm{N}(\mathrm{CZ} \times$ parent cent. $\times$ cohort $)$ & 13578 & 13578 & 13578 & 13578 \\
\hline Effect of a 1sd $\downarrow \beta$ by parents' percentile: & & & & \\
\hline 10th, elem & 2.817 & 2.467 & 7.599 & 7.248 \\
\hline 25 th, elem & 1.761 & 1.452 & 6.311 & 6.033 \\
\hline 90th, elem & -2.816 & -2.945 & 0.727 & 0.766 \\
\hline 10th, high & 1.342 & 1.286 & 4.101 & 4.075 \\
\hline 25th, high & 1.041 & 0.989 & 3.809 & 3.785 \\
\hline 90th, high & -0.262 & -0.298 & 2.545 & 2.529 \\
\hline
\end{tabular}

Note: The table shows OLS (columns 1 and 2) and 2SLS second-stage estimates (columns 3 and 4) of the parameters in equation (11). The dependent variable is children's income percentile in the national distribution for each parental income percentile in the distribution of each $\mathrm{CZ}$, for cohorts 1980 to 1986 . The variable $\beta$ is the OLS estimate of the slope coefficient in equation (6), computed separately for each state and cohort, and standardized across all states and cohorts. The variable parent centile is the percentile of parents in the national income distribution. In columns 3 and 4 , the variable $\beta$ is instrumented with $\beta$ simulated, estimated as $\beta$ using simulated revenues instead of actual revenues. The variables reform in elementary school, reform in middle school, and reform in high school equal one for cohorts and states for which a reform hit during elementary, middle, and high school, respectively. All specifications include parent percentile and cohort fixed effects; columns 1 and 3 include CZ fixed effects, and columns 2 and 4 include state fixed effects. Standard errors in parentheses are clustered at the state and birth cohort level. The sample is restricted to California, Colorado, Florida, Georgia, Illinois, Kentucky, Louisiana, Massachusetts, Michigan, Minnesota, Montana, Nebraska, New Jersey, New York, North Dakota, Ohio, Pennsylvania, Utah, Texas, and Wisconsin. ${ }^{* * *} \mathrm{p}<0.01,{ }^{* *} \mathrm{p}<0.05,{ }^{*} \mathrm{p}<0.1$. 
Table VII: Heterogeneous Effects of School Finance Equalization by CZs' Income Inequality. 2SLS, Dependent Variable is Children's Income Percentile

\begin{tabular}{|c|c|c|c|c|}
\hline & \multicolumn{2}{|c|}{ Low Inequality } & \multicolumn{2}{|c|}{ High Inequality } \\
\hline & $(1)$ & (2) & (3) & (4) \\
\hline$\beta$ & $\begin{array}{l}-4.8634 \\
(3.2733)\end{array}$ & $\begin{array}{l}-4.6557 \\
(3.2213)\end{array}$ & $\begin{array}{l}-6.3731^{*} \\
(3.1138)\end{array}$ & $\begin{array}{l}-6.4087^{*} \\
(3.0938)\end{array}$ \\
\hline$\beta \times$ parent centile & $\begin{array}{c}0.0269^{* *} \\
(0.0077)\end{array}$ & $\begin{array}{c}0.0237^{* *} \\
(0.0072)\end{array}$ & $\begin{array}{c}0.0221^{* * *} \\
(0.0025)\end{array}$ & $\begin{array}{c}0.0235^{* * *} \\
(0.0031)\end{array}$ \\
\hline Parent centile FE & Yes & Yes & Yes & Yes \\
\hline State FE & No & Yes & No & Yes \\
\hline CZ FE & Yes & No & Yes & No \\
\hline Cohort FE & Yes & Yes & Yes & Yes \\
\hline $\mathrm{N}(\mathrm{CZ} \times$ parent cent. $\times$ cohort $)$ & 5586 & 5586 & 7950 & 7950 \\
\hline \multicolumn{5}{|c|}{ Effect of a 1 sd $\downarrow \beta$ by parents' percentile: } \\
\hline 10th & 4.595 & 4.418 & 6.152 & 6.174 \\
\hline 10th [p-value] & [0.208] & {$[0.218]$} & [0.096] & [0.093] \\
\hline 25 th & 4.191 & 4.062 & 5.821 & 5.822 \\
\hline 25th [p-value] & [0.242] & {$[0.251]$} & [0.111] & [0.109] \\
\hline 90th & 2.444 & 2.520 & 4.385 & 4.295 \\
\hline 90th [p-value] & [0.470] & [0.458] & [0.210] & [0.215] \\
\hline
\end{tabular}

Note: The dependent variable is children's income percentile in the national distribution for each parental income percentile in the distribution of each CZ, for cohorts 1980 to 1986 . The variable $\beta$ is the OLS estimate of the slope coefficient in equation (6), computed separately for each state and cohort, and standardized across all states and cohorts. The variable parent centile is the percentile of parents in the national income distribution. The variable $\beta$ is instrumented by $\beta$ simulated, estimated as $\beta$ using simulated revenues instead of actual revenues. All specifications include parent percentile and cohort fixed effects; columns 1 and 3 include CZ fixed effects, and columns 2 and 4 include state fixed effects. "Low Inequality" ("High Inequality") refers to CZs below (above) the median level of income inequality, measured as the percentage difference in average income between the richest and poorest district in each $\mathrm{CZ}$ in 1990. Standard errors in parentheses are clustered at the state and birth cohort level. The sample is restricted to California, Colorado, Florida, Georgia, Illinois, Kentucky, Louisiana, Massachusetts, Michigan, Minnesota, Montana, Nebraska, New Jersey, New York, North Dakota, Ohio, Pennsylvania, Utah, Texas, and Wisconsin. ${ }^{* *} \mathrm{p}<0.01,{ }^{* *} \mathrm{p}<0.05,{ }^{*} \mathrm{p}<0.1$. 
Table VIII: Heterogeneous Effects of School Finance Equalization by CZs' Income Segregation. 2SLS, Dependent Variable is Children's Income Percentile

\begin{tabular}{|c|c|c|c|c|}
\hline & \multicolumn{2}{|c|}{ Low Segregation } & \multicolumn{2}{|c|}{ High Segregation } \\
\hline & (1) & (2) & (3) & (4) \\
\hline$\beta$ & $\begin{array}{l}-5.4864^{*} \\
(2.6903)\end{array}$ & $\begin{array}{l}-5.4230^{*} \\
(2.6721)\end{array}$ & $\begin{array}{l}-6.0725 \\
(3.2122)\end{array}$ & $\begin{array}{l}-6.0227 \\
(3.2019)\end{array}$ \\
\hline$\beta \times$ parent centile & $\begin{array}{c}0.0253^{* * *} \\
(0.0067)\end{array}$ & $\begin{array}{c}0.0242^{* * *} \\
(0.0065)\end{array}$ & $\begin{array}{c}0.0237^{* * *} \\
(0.0034)\end{array}$ & $\begin{array}{c}0.0244^{* * *} \\
(0.0037)\end{array}$ \\
\hline Parent centile FE & Yes & Yes & Yes & Yes \\
\hline State FE & No & Yes & No & Yes \\
\hline CZ FE & Yes & No & Yes & No \\
\hline Cohort FE & Yes & Yes & Yes & Yes \\
\hline $\mathrm{N}(\mathrm{CZ} \times$ parent cent. $\times$ cohort $)$ & 5880 & 5880 & 7698 & 7698 \\
\hline \multicolumn{5}{|c|}{ Effect of a 1sd $\downarrow \beta$ by parents' percentile: } \\
\hline 10th & 5.233 & 5.181 & 5.835 & 5.778 \\
\hline 10th [p-value] & [0.098] & [0.099] & [0.120] & [0.122] \\
\hline 25 th & 4.853 & 4.819 & 5.479 & 5.411 \\
\hline 25th [p-value] & [0.117] & [0.118] & [0.140] & [0.144] \\
\hline 90th & 3.207 & 3.249 & 3.935 & 3.822 \\
\hline 90th [p-value] & [0.265] & {$[0.262]$} & {$[0.274]$} & [0.287] \\
\hline
\end{tabular}

Note: The dependent variable is children's income percentile in the national distribution for each parental income percentile in the distribution of each $\mathrm{CZ}$, for cohorts 1980 to 1986 . The variable $\beta$ is the OLS estimate of the slope coefficient in equation (6), computed separately for each state and cohort, and standardized across all states and cohorts. The variable parent centile is the percentile of parents in the national income distribution. The variable $\beta$ is instrumented by $\beta$ simulated, estimated as $\beta$ using simulated revenues instead of actual revenues. All specifications include parent percentile and cohort fixed effects; columns 1 and 3 include CZ fixed effects, and columns 2 and 4 include state fixed effects. "Low Segregation" ("High Segregation") refers to CZs below (above) the median level of income segregation across all CZs, where income segregation is measured with a Theil index calculated across districts within each CZ using data from 1990. Standard errors in parentheses are clustered at the state and birth cohort level. The sample is restricted to California, Colorado, Florida, Georgia, Illinois, Kentucky, Louisiana, Massachusetts, Michigan, Minnesota, Montana, Nebraska, New Jersey, New York, North Dakota, Ohio, Pennsylvania, Utah, Texas, and Wisconsin. ${ }^{* * *} \mathrm{p}<0.01,{ }^{* *} \mathrm{p}<0.05,{ }^{*} \mathrm{p}<0.1$. 
Table IX: School Finance Equalization and School Inputs. OLS and 2SLS, Dependent Variable is the Number of Teachers per Student

\begin{tabular}{lccccc}
\hline \hline & \multicolumn{2}{c}{ OLS } & & \multicolumn{2}{c}{ 2SLS } \\
\cline { 2 - 3 } \cline { 5 - 6 } & $(1)$ & $(2)$ & & $(3)$ & $(4)$ \\
\hline$\beta \times$ income in the $1^{\text {st }}$ quartile & $-0.0029^{*}$ & $-0.0060^{* *}$ & & $-0.0051^{*}$ & $-0.0076^{* *}$ \\
& $(0.0015)$ & $(0.0024)$ & & $(0.0028)$ & $(0.0032)$ \\
$\beta \times$ income in the $2^{\text {nd }}$ quartile & -0.0002 & 0.0010 & & -0.0027 & -0.0035 \\
& $(0.0015)$ & $(0.0012)$ & & $(0.0026)$ & $(0.0029)$ \\
$\beta \times$ income in the $3^{\text {rd }}$ quartile & 0.0017 & 0.0018 & & -0.0009 & 0.0003 \\
& $(0.0018)$ & $(0.0023)$ & & $(0.0025)$ & $(0.0027)$ \\
$\beta \times$ income in the $4^{\text {th }}$ quartile & 0.0021 & 0.0021 & & -0.0000 & 0.0017 \\
& $(0.0017)$ & $(0.0036)$ & & $(0.0031)$ & $(0.0040)$ \\
Year FE & Yes & Yes & & Yes & Yes \\
State FE & Yes & No & & Yes & No \\
District FE & No & Yes & & No & Yes \\
Quartile FE & Yes & Yes & & Yes & Yes \\
\hline N (district $\times$ year) & 110833 & 110773 & & 110833 & 110773 \\
Y-mean & 0.072 & 0.072 & 0.072 & 0.072 \\
\hline \hline
\end{tabular}

Note: The dependent variable is the total number of teachers employed in a district, divided by the total number of students; observations are at the district-year level and cover years 1988-2004. The variable $\beta$ is defined as the OLS estimate of the slope coefficient in equation (6), computed separately for each state and year, and standardized across all states and years. The variable income in the $X^{\text {th }}$ quartile equals 1 for districts with median household income in the $X^{\text {th }}$ quartile of the national distribution in 1990. Columns 1 and 2 estimate OLS; columns 3 and 4 estimate 2SLS, with $\beta^{\text {sim }}$ (obtained using simulated revenues instead of actual revenues) as an instrument for $\beta$. All specifications include year fixed effects; columns 1 and 3 include state fixed effects, and columns 2 and 4 include district fixed effects. Standard errors in parentheses are clustered at the state and year level. The sample is restricted to California, Colorado, Florida, Georgia, Illinois, Kentucky, Louisiana, Massachusetts, Michigan, Minnesota, Montana, Nebraska, New Jersey, New York, North Dakota, Ohio, Pennsylvania, Utah, Texas, and Wisconsin. ${ }^{* * *} \mathrm{p}<0.01,{ }^{* *} \mathrm{p}<0.05,{ }^{*} \mathrm{p}<0.1$. 
Table X: School Finance Equalization and College Enrollment. 2SLS, Dependent Variable is Children's Probability of College Enrollment at Age 19

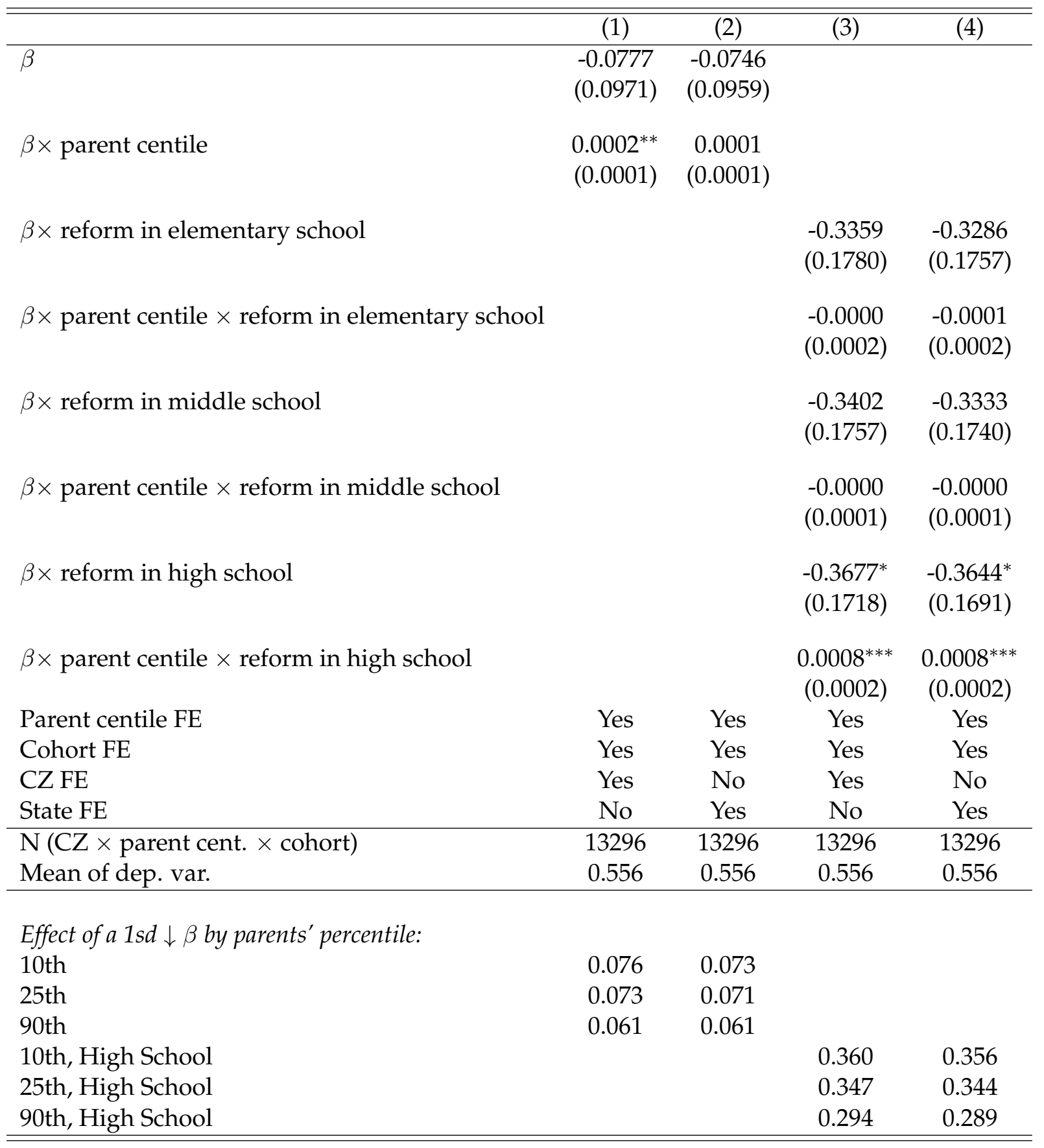

Note: The dependent variable is the probability of college enrollment by age 19 for each parental income percentile in the distribution of each CZ, for cohorts 1984 to 1990 . The variable $\beta$ is the OLS estimate of the slope coefficient in equation (6), computed separately for each state and cohort, and standardized across all states and cohorts. The variable parent centile is the percentile of parents in the national income distribution. The variable $\beta$ is instrumented with $\beta$ simulated, estimated using simulated revenues instead of actual revenues. The variables reform in elementary school, reform in middle school, and reform in high school equal one for cohorts and states for which a reform hit during elementary, middle, and high school, respectively. All specifications include parent percentile and cohort fixed effects; columns 1 and 3 include CZ fixed effects, while columns 2 and 4 include state fixed effects. Standard errors in parentheses are clustered at the state and birth cohort level. The sample is restricted to California, Colorado, Florida, Georgia, Illinois, Kentucky, Louisiana, Massachusetts, Michigan, Minnesota, Montana, Nebraska, New Jersey, New York, North Dakota, Ohio, Pennsylvania, Utah, Texas, and Wisconsin. ${ }^{* * *} \mathrm{p}<0.01,{ }^{* *} \mathrm{p}<0.05$, ${ }^{*} \mathrm{p}<0.1$. 